\title{
Development of extended WRF variational data assimilation system (WRFDA) for WRF non-hydrostatic mesoscale model
}

\author{
Sujata Pattanayak* and U C Mohanty \\ School of Earth Ocean and Climate Sciences, Indian Institute of Technology, Bhubaneswar, Toshali Bhavan, Satya \\ Nagar, Bhubaneswar 751 00\%, India. \\ *Corresponding author.e-mail: sujata05@gmail.com
}

MS received 3 March 2017; revised 8 October 2017; accepted 28 October 2017; published online 22 May 2018

The paper intends to present the development of the extended weather research forecasting data assimilation (WRFDA) system in the framework of the non-hydrostatic mesoscale model core of weather research forecasting system (WRF-NMM), as an imperative aspect of numerical modeling studies. Though originally the WRFDA provides improved initial conditions for advanced research WRF, we have successfully developed a unified WRFDA utility that can be used by the WRF-NMM core, as well. After critical evaluation, it has been strategized to develop a code to merge WRFDA framework and WRF-NMM output. In this paper, we have provided a few selected implementations and initial results through single observation test, and background error statistics like eigenvalues, eigenvector and length scale among others, which showcase the successful development of extended WRFDA code for WRFNMM model. Furthermore, the extended WRFDA system is applied for the forecast of three severe cyclonic storms: Nargis (27 April-3 May 2008), Aila (23-26 May 2009) and Jal (4-8 November 2010) formed over the Bay of Bengal. Model results are compared and contrasted within the analysis fields and later on with high-resolution model forecasts. The mean initial position error is reduced by $33 \%$ with WRFDA as compared to GFS analysis. The vector displacement errors in track forecast are reduced by $33,31,30$ and $20 \%$ to $24,48,72$ and $96 \mathrm{hr}$ forecasts respectively, in data assimilation experiments as compared to control run. The model diagnostics indicates successful implementation of WRFDA within the WRF-NMM system.

Keywords. WRF-NMM; WRFDA; single observation test; eigenvalues; eigenvector; correlation; tropical cyclone; Bay of Bengal.

\section{Introduction}

The Numerical Weather Prediction (NWP) is an initial value problem and hence needs an accurate representation of the initial state of the atmosphere to determine its realistic future state. The forecast performance of any mesoscale model critically depends on the quality of initial values (Pielke et al. 2006). The data assimilation approach provides balanced and reasonably accurate initial state of the atmosphere using viable observed information available at the irregular grid. Therefore, observational data assimilation approaches that ingest local observations are vital for improving analyses of mesoscale models (Dale 1991). 
The data assimilation techniques have been developed since late 1950 to exploit the benefit of meteorological observations from different observing systems. In earlier years, various model initialization procedures like objective analysis (Cressman 1959), optimum interpolation (OI) by Gandin (1963, 1988), etc., have been developed. There are various techniques of data assimilation such as (i) Optimal Interpolation algorithm (OI; Gandin 1963), (ii) Newtonian relaxation (nudging, Stauffer and Seaman 1990), (iii) three-dimensional variational data assimilation (3DVAR; Courtier and Talagrand 1987; Courtier et al. 1993), (iv) fourdimensional variational data assimilation (4DVAR; Derber 1989; Ide et al. 1997), and (v) Kalman filtering (Kalman 1960). The major difference between variational and interpolation methods of data assimilation is that while interpolation methods use observational data in the vicinity of a model grid point, variational methods use the available data over the entire domain and globally minimize the errors. As a consequence of this, initial data generated by variational methods are less noisy and in better balance than those produced by interpolation algorithms. Therefore, much effort has been put in the development of variational data assimilation systems to replace previously used schemes, for example, optimum interpolation (Parrish and Derber 1992; Lorenc et al. 2000). Advantages of the variational approach include (a) the ability to assimilate observed quantities related nontrivially to standard atmospheric variables (e.g., radiances) and (b) the imposition of dynamic balance either implicitly through the inclusion of the forecast model itself (4DVAR) or explicitly through the use of balance equations (3DVAR).

With the advent of new observation sources, such as satellites, radar, and many new remote sensing technologies, meteorological observations are now available at more spatial locations. The highresolution observations are not fully utilized in case the resolution of a model is very coarse. Mesoscale data assimilation is required for improving the forecast skill of the mesoscale weather phenomena. In recent years, high-resolution mesoscale models with 3D/4DVAR are being increasingly applied for studying meteorological phenomena (Kalnay 2003; Barker et al. 2004, 2012; Jianfeng et al. 2005; Guidard et al. 2006; Huang et al. 2009). The $3 \mathrm{D} / 4 \mathrm{DVAR}$ is capable of directly incorporating satellite radiance, radar reflectivity and radial velocity in the numerical model (Gao et al. 1999; $\mathrm{Wu}$ et al. 2000; Xiao et al. 2005, 2007). In recent years, the need for higher quality and more versatile data assimilation technique has become apparent. Additional demands on data assimilation techniques have resulted for several different reasons. First, the increased density, frequency and quality of data network with increased observing system needs the improvement of data assimilation system. Second, the quality and quantity of NWP models necessitate appropriate data assimilation package individually.

In recent years, the numerical models have been widely used (Prasad et al. 1997; Mandal et al. 2004; Mohanty et al. 2004; Bhaskar Rao et al. 2006; Pattanayak and Mohanty 2008; Pattanaik and Rama Rao 2009; Srinivas et al. 2013a, b; Das et al. 2014, etc.) to simulate tropical cyclones over the Bay of Bengal (BoB). More precisely, the assimilation of observational datasets improves the performances of the models in forecast of tropical cyclones over the BoB (Mandal et al. 2006; Sandeep et al. 2006; Singh et al. 2008, 2011, 2012; Osuri et al. 2011; Prashant et al. 2012; Srinivas et al. 2010, 2012; Yesubabu et al. 2013; Greeshma et al. 2015, etc.). These studies used Mesoscale Model V5.0 (MM5) model with Cressman's technique and Advance Weather Research and Forecasting System (ARW) model with Weather Research Forecasting Data Assimilation (WRFDA) approach.

The non-hydrostatic mesoscale model core of weather research forecasting system (WRF-NMM) is a fully compressible, non-hydrostatic mesoscale model with a hydrostatic option (Janjic et al. 2001; Janjic 2003a, b). Its vertical coordinate is a hybrid sigma-pressure coordinate. The grid staggering is the Arakawa E-grid. The model uses a forwardbackward scheme for horizontally propagating fast waves, an implicit scheme for vertically propagating sound waves, Adams-Bashforth scheme for horizontal advection, and Crack-Nicholson scheme for vertical advection. The same time step is used for all terms. The dynamics conserve a number of first and second order quantities, including energy and enstrophy (Janjic 1984). This model supports a variety of capabilities, including real-data simulations, full physics options, non-hydrostatic and hydrostatic (runtime) option, one-way and two-way nesting and applications ranging from meters to thousands of kilometers.

Modern NWP data assimilation systems use information from a range of sources in order to provide the best estimation of the atmospheric state (reanalysis) at a particular time. Estimates of atmospheric variables from (incomplete and 
imperfect) observation systems may be supplemented with information from previous forecasts (i.e., background or first-guess), detailed error statistics. In recent years, much effort has been given in the development of variational data assimilation systems (Barker et al. 2004). The WRF variational data assimilation system (WRFDA) developed at the National Center for Atmospheric Research (NCAR), USA is mainly devoted for providing an improved initial condition to NCAR's Advanced Research WRF (ARW) version of WRF. The latest WRFDA Version 3.0 released has the capability to assimilate all the conventional, radar (refractivity and radial velocity), and GPS (refractivity and Total Zenith delay) data. To get details about WRFDA, please refer to http://www.wrfmodel.org/development/group/WG4. Hence, it was decided to develop a utility, to integrate WRFDA with WRF-NMM in the sense that WRFDA should be able to accept WRF-NMM forecast as its first guess (FG) and after analysis, the updated FG is acceptable to WRF-NMM.

This paper describes the development strategy followed to initialize WRF-NMM with WRFDA with a few implementation results. The initial goals in the development of 3DVAR for WRF-NMM include the following.

- Release as a research community data assimilation system.

- A new assimilation package for the operational community, as WRF-NMM is an operational model in leading organizations throughout the world.

Section 2 provides details of the development strategy. The results and discussions are presented in section 3 and the conclusions are in section 4 .

\section{Development strategy}

Currently, WRFDA does analysis on non-staggered Arakawa-A grid. The main inputs from WRFARW model to WRFDA, are the wind ( $\mathrm{U}$ and $\mathrm{V}$ ) components, perturbations of potential temperature, surface pressure, height, mixing ratio on the staggered Arakawa-C grid at sigma levels. The perturbation variables here are defined as deviations from a time-invariant hydrostatically balanced reference state in the usual sense of WRF-ARW. The vertical coordinates are defined in terms of terrain following hydrostatic pressure vertical coordinate $(\eta)$ as follows:

$$
\eta=\left(p_{h}-p_{h t}\right) / \mu
$$

where

$$
\mu=p_{h s}-p_{h t}
$$

$p_{h}$ is the hydrostatic component of the pressure, and $p_{h s}$ and $p_{h t}$, which refer to the values along the surface and top boundaries, respectively.

Analysis control variables for WRFDA are stream function $(\psi)$, unbalanced (in a statistical sense) part of velocity potential $(\chi)$, temperature $(T)$, surface pressure (Psfc) and the moisture (pseudo relative humidity).

In order to build up the strategy to input WRFNMM field in WRFDA, it is very much essential to survey what type, and at what grid the WRFNMM fields are available. WRF-NMM has been built up with an Arakawa E-grid staggering with rotating lat.-long. projection. In rotated lat.-long. projection, the rotation of the natural, geodesic latitude, longitude has been done in such a way that, the intersection of the equator and prime meridian intersects at the center of the computational domain. This rotated framework provides more uniform horizontal grid spacing and reduces the convergence of the meridians over the domain. The transformation equations (equation 1) can be described as follows:

$$
\begin{aligned}
& \Lambda=\operatorname{arctg} \frac{\cos \varphi \sin \left(\lambda-\lambda_{0}\right)}{\cos \varphi_{0} \cos \varphi \cos \left(\lambda-\lambda_{0}\right)+\sin \varphi_{0} \sin \varphi} \\
& \Phi=\arcsin \left(\cos \varphi_{0} \sin \varphi-\sin \varphi_{0} \cos \varphi \cos \left(\lambda-\lambda_{0}\right)\right)
\end{aligned}
$$

where

$$
\begin{aligned}
& \varphi=\arcsin \left(\sin \varphi_{0} \cos \Phi \cos \Lambda+\cos \varphi_{0} \sin \Phi\right) \\
& \lambda=\lambda_{0}+\arcsin \left(\frac{\sin \Lambda \cos \Phi}{\cos \varphi_{0}}\right) .
\end{aligned}
$$

As described above, currently WRFDA does the analysis on staggered Arakawa A-grid with a minimum requirement of above-stated fields. However, WRF-NMM is designed in staggered Arakawa E-grid in which, there are some deviations like sensible temperature $(T)$, specific humidity $(Q)$, and geopotential height (FIS) found in the output variable list. Also, there is no map factor concept available in WRF-NMM, as it does not require for rotated lat.-long. projection. The WRF-NMM deals with the pressure-sigma hybrid vertical coordinate, so there is a concept of sigma value in pressure domain (ETA1, $0<\eta_{1}<1, \eta_{2}=0$ ) and 


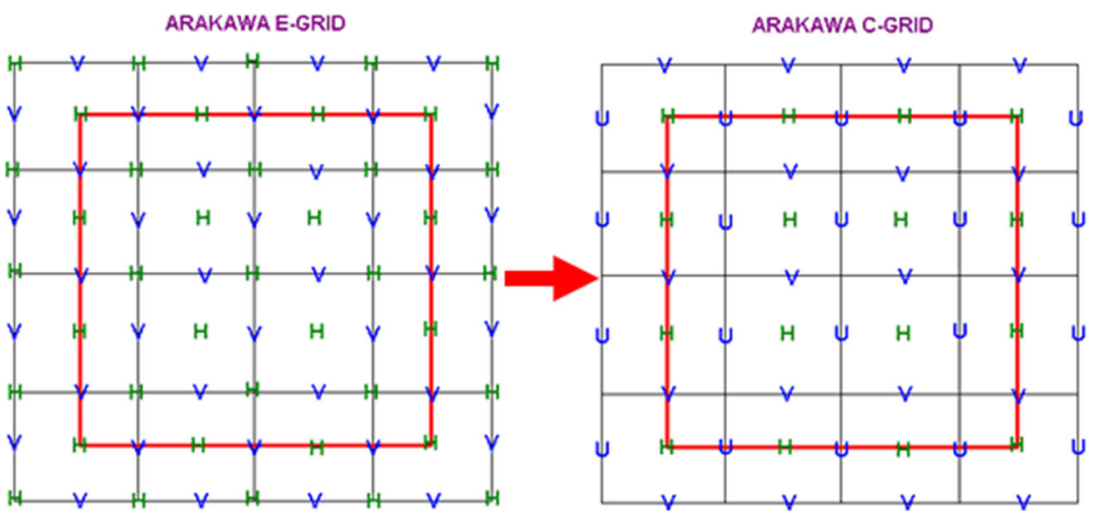

Figure 1. Representation of Arakawa E-grid (left) and Arakawa C-grid (right) panels.

sigma value in sigma domain (ETA2, $0<\eta_{2}<1$, $\left.\eta_{1}=1\right)$ is available. So, in order to provide appropriate variables to WRFDA with a suitable grid structure, a utility has been developed to convert certain fields in the desired format. The representation of Arakawa-E grid and the Arakawa$\mathrm{C}$ grid is provided in figure 1 .

After carefully examining the basic WRFDA framework and WRF-NMM output fields, this work was visualized to be achieved in four stages.

(a) Preparing desired WRF-NMM fields as initial FG input to WRFDA.

(b) Upgrading WRFDA code for WRF-NMM.

(c) Updating desired WRF-NMM field with WRFDA analysis increments.

(d) Generation of background error for WRFNMM suited to WRFDA.

\section{(a) Preparing desired WRF-NMM fields as initial FG input to WRFDA}

Keeping in view that basic WRFDA framework is mainly devoted to WRF-ARW, it was decided to perform this job outside WRFDA. Accordingly, a utility named, ' $\mathrm{E} 2 \mathrm{C}$ ' is written which mainly does the grid conversion (from Arakawa-E to Arakawa-C grid) of the desired WRF-NMM fields. It was essential because currently WRF-ARW and WRFDA share common registry and so without changing registry, it was not possible to read WRF-NMM output file. With this procedure, all the WRF I/O Applications Program Interface (I/O API), especially the Message Passing Interface (MPI) features may be utilized as such without changing WRF 'Registry'. All WRF-NMM variables sharing the same name (with similar meaning) as in WRF-ARW, like wind components ( $\mathrm{U}$ and $\mathrm{V}$ ), are packed by 'E2C' converter as such. For WRF-NMM specific variables, like the mass of the pressure regime (PDTOP), sigma values for the sigma regime (ETA1), sigma values for the pressure regime (ETA2), etc., a parallel suitable array (which currently WRFDA do not use) is identified in the WRF-ARW list of variables to pack these variables. A complete list of WRF-NMM variables packed by 'E2C' converter with details against which WRF-ARW name it is packed, units, etc., is described in Appendix A.

\section{(b) Upgrading WRFDA code for WRF-NMM}

Since the beginning of WRFDA development, it has been a policy to maintain a single version (unified) of WRFDA code. Keeping this in view, following new variables (along with its assigned values) have been added in WRFDA for branching the code logic if it is aimed to run with WRF-NMM FG input.

$$
\begin{aligned}
& \text { FG_FORMAT_WRF_ARW_REGIOANL }=1 \\
& \text { FG_FORMAT_WRF_NMM_REGIOANL }=2 \\
& \text { FG_FORMAT_WRF_ARW_GLOBAL }=3 \\
& \text { FG_FORMAT_KMA_GLOBAL }=4
\end{aligned}
$$

These names are self-explanatory. WRFDA code reads it against 'FG_FORMAT', which is one of its 'namelist' variables. Thus, depending upon the value of 'FG_FORMAT', WRFDA does branching for operations like locating observation co-ordinate, forward and adjoint operations, etc. WRF-NMM specific 'rotated lat.-long.' projection has been included in WRFDA as a separate routine. For maintaining consistency with the original WRFDA code, following new subroutines have also been introduced.

da_setup_firstguess_wrf_nmm_regional da_transfer_wrf_nmm_regional_to_xb da_transfer_xatowrf_nmm_regional 
da_write_increments_for_wrf_nmm_regional da_llxy_rotated_latlon

Main functions of these subroutines are described in Appendix B. Upgraded WRFDA has passed all the transform tests collectively and individually, including the 'adjoint'. It has also been tested to ensure that it gives similar results (compared to the original code) when it is run with WRFARW FG input. It is also verified that serial, single and multiple CPU runs should produce same results.

\section{(c) Updating desired WRF-NMM field with WRFDA analysis increments}

Currently, when WRFDA is running with the WRF-ARW (regional or global) FG, updated FG is directly written in 'analysis' file. We have to deviate from this practice when FG input is from WRF-NMM. This happens because the FG is not the original WRF-NMM output, but an intermediate file created in step (a) as mentioned above. It holds only the desired input fields for WRFDA and not all the WRF-NMM fields. To overcome this problem, it was decided to write (currently in binary format) the analysis increments in a separate file. A separate utility, named 'A2E', is developed to read WRFDA analysis increments and update the original WRF-NMM fields. This utility needs to be run outside WRFDA. In this procedure (from Arakawa-A to Arakawa-E grid, the interpolation error is also reduced as this operation is done only on increments and not on the full WRF-NMM fields.

\section{(d) Generation of background error for WRF-NMM suited to WRFDA}

To achieve this, 'gen_be' utility of WRFDA has been updated to accept WRF-NMM output. Currently, there are basically five stages to run 'gen_be'. To accommodate WRF-NMM input to 'gen_be', it is only the 'gen_be_stage0' needs updating. Accordingly, the main source code dealing with 'gen_be_stage0' namely, 'gen_be_stage0_wrf.f90' has been modified. To run this utility with WRFNMM case, one needs to run the E2C converter on WRF-NMM forecasts and this goes as input to 'gen_be_stage0' program. To keep track whether it is WRF-ARW or WRF-NMM, a new ASCII variable named WRF_OPTION has been introduced, which currently, can accept any of the following three values.

\section{WRF_OPTION = 'ARW_GLOABL'}

or

$=$ 'ARW_REGIONAL'

or

$=$ 'NMM_REGIONAL'.

Thus, depending on user's WRF_OPTION choice, which is self-explanatory, the 'gen_be_stage0' runs accordingly. The WRF_OPTION needs to be specified at runtime (via 'gen_be' wrapper script). After the update, 'gen_be_stage0' has been tested independently and also collectively with all other stages.

\section{Results and discussions}

The updated code has been tested over Indian region $\left(15^{\circ} \mathrm{S}-45^{\circ} \mathrm{N}, 30^{\circ} \mathrm{E}-130^{\circ} \mathrm{E}\right)$. The WRFNMM model has been integrated for a 1-month period from 15 October, 2010 to 15 November, 2010 for generation of background error covariance from the forecast input from 00 to 12 UTC. The National Meteorological Center (NMC) method has been chosen to produce the desired WRF-NMM background error statistics for updated WRFDA. The updated code has been tested through single observation test and by proper error statistics from the background error calculation.

Figure 2 represents the flowchart used to develop a strategy to build the utility to initialize WRFNMM with WRFDA system. The WRFDA system has mainly three inputs like: (1) $\mathrm{X}_{\mathrm{b}}$ array from the background pre-processing, (2) $\mathrm{Y}^{0}$ from the observation pre-processing and (3) $\mathrm{B}_{0}$, the background error statistics. Before packing the WRF-NMM pre-processing fields in the specified $\mathrm{X}^{\mathrm{b}}$ array, it should be converted to the needed format through the grid conversion utility. Hence, the output from the pre-processing real programme is the input for the converter utility. However, the converter utility will be used for the necessary WRF-NMM fields desired by the WRFDA system. The observation pre-processor (OBSPROC) reads the observation file in the specified 'LITTLE_R' format (a legendary ASCII format, in use since MM5 era), removes the observation outside the time loop and domain and produces the $\mathrm{Y}^{0}$ array. Again, before generating the background error from the WRFNMM model, the desired forecast fields need to be converted through the grid conversion utility. 


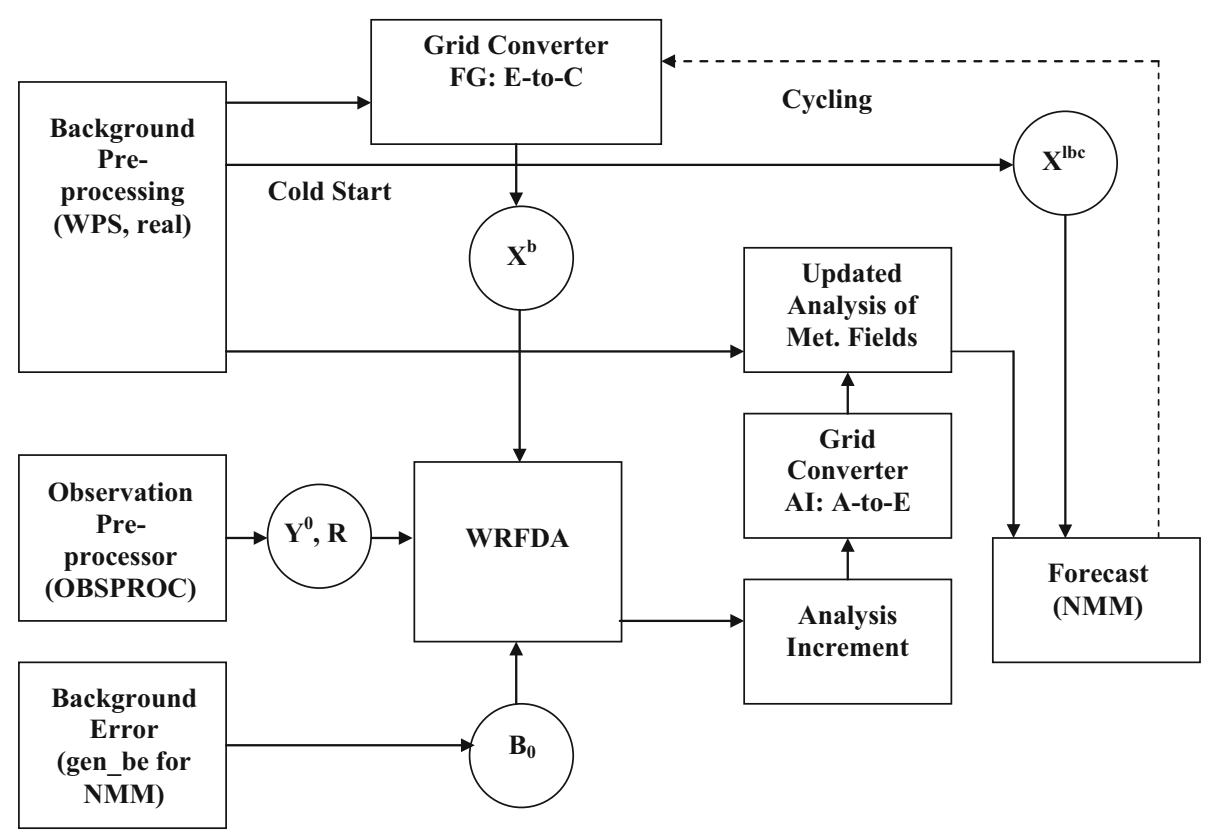

Figure 2. Schematic diagram of the modified WRFDA system representing the relationship between datasets (circles) and algorithms (rectangles) used in the initialization of the WRF-NMM model with WRFDA.

Taking all the three inputs (as described above), the WRFDA system has been integrated, which produces the analysis as well as the analysis increment file as output. The analysis increment file will be used as the input for the backward interpolation, i.e., from C-grid to E-grid and which can be further added up with the unconverted initial condition generated through the pre-processing system to update the same. This updated initial condition now can be used as the initial condition for the model integration.

Figure 3 shows the pattern of the basic fields like $\mathrm{U}, \mathrm{V}, \mathrm{T}$, and $\mathrm{Q}$ as it undergoes through the grid conversion utility programme. The left panel [i.e., figure $3(\mathrm{a}-\mathrm{d})$ ] is consisting of the Arakawa E-grid structure of the above-mentioned fields and right panel [i.e., figure $3(\mathrm{e}-\mathrm{h})$ ] is for the Arakawa C-grid structure of the corresponding field. The conversion of fields from one grid structure to the other shows that for the velocity and mass fields, the pattern is almost conserved after going through the grid conversion utility.

\subsection{DVAR single observation test}

The multivariate, three-dimensional nature of 3DVAR's background error covariance (B) is examined by studying 3DVAR's response to single bogus zonal and meridional winds, temperature and humidity observations. In WRF-Var system, the single observation test is used as a proof-of-concept to determine the performance of a single observation through the established correlations among WRF-Var variables (Wu et al. 2002). For this purpose, a single $\mathrm{u}$-wind and temperature perturbation test are applied at the center of the computational domain $\left(11.8^{\circ} \mathrm{N}, 81.7^{\circ} \mathrm{E}\right)$ and 25th sigma level. The innovation (observation minus background; $\mathrm{O}-\mathrm{B}$ ) of the single $\mathrm{u}$-wind and temperature was assigned as $1 \mathrm{~ms}^{-1}$ and $1 \mathrm{~K}$ respectively. Figure $4(\mathrm{a}-\mathrm{c})$ represents the response of the analysis increment to the single observation $\mathrm{u}$-wind of $1 \mathrm{~ms}^{-1}$. A spread of $0.9 \mathrm{~ms}^{-1}$ is observed in u-increment (figure 4a). The response in $\mathrm{v}$-wind (figure 4b) supports the cyclonic and anti-cyclonic circulation to the north and south of the $\mathrm{u}$-increment location, respectively. The temperature response (figure 4c) is large in comparison to $\mathrm{u}$ - and $\mathrm{v}$-wind response with the innovation of $1 \mathrm{~ms}^{-1} \mathrm{u}$-wind. The spatial spreading is also more for temperature. Figure 4(d-f) demonstrates the response of the analysis increment to the single temperature observation of $1 \mathrm{~K}$. The horizontal temperature increment (figure $4 \mathrm{f}$ ) of about $400 \mathrm{~km}$ is noticed. The response of temperature increment in u- (figure 4d) and v-wind (figure 4e) component shows relatively large spatial impact (spread) with less magnitude. The results clearly demonstrate the successful up-gradation of WRF-Var system for WRF-NMM. 


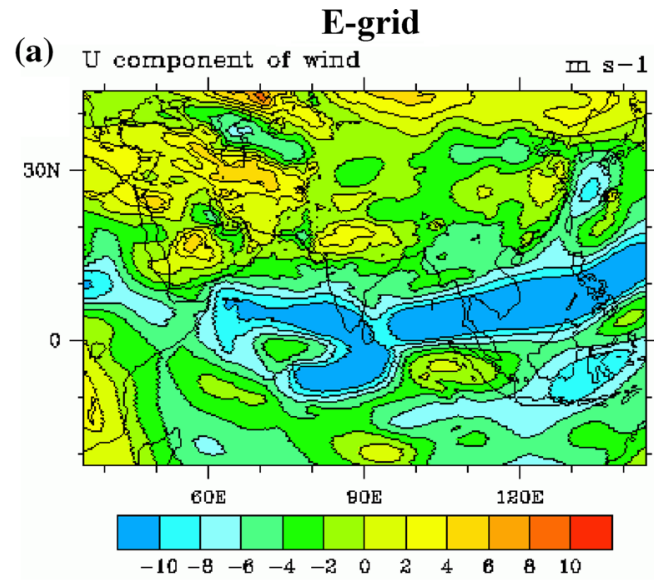

(b) $\mathrm{v}$ component of wind $\mathrm{m} s-1$
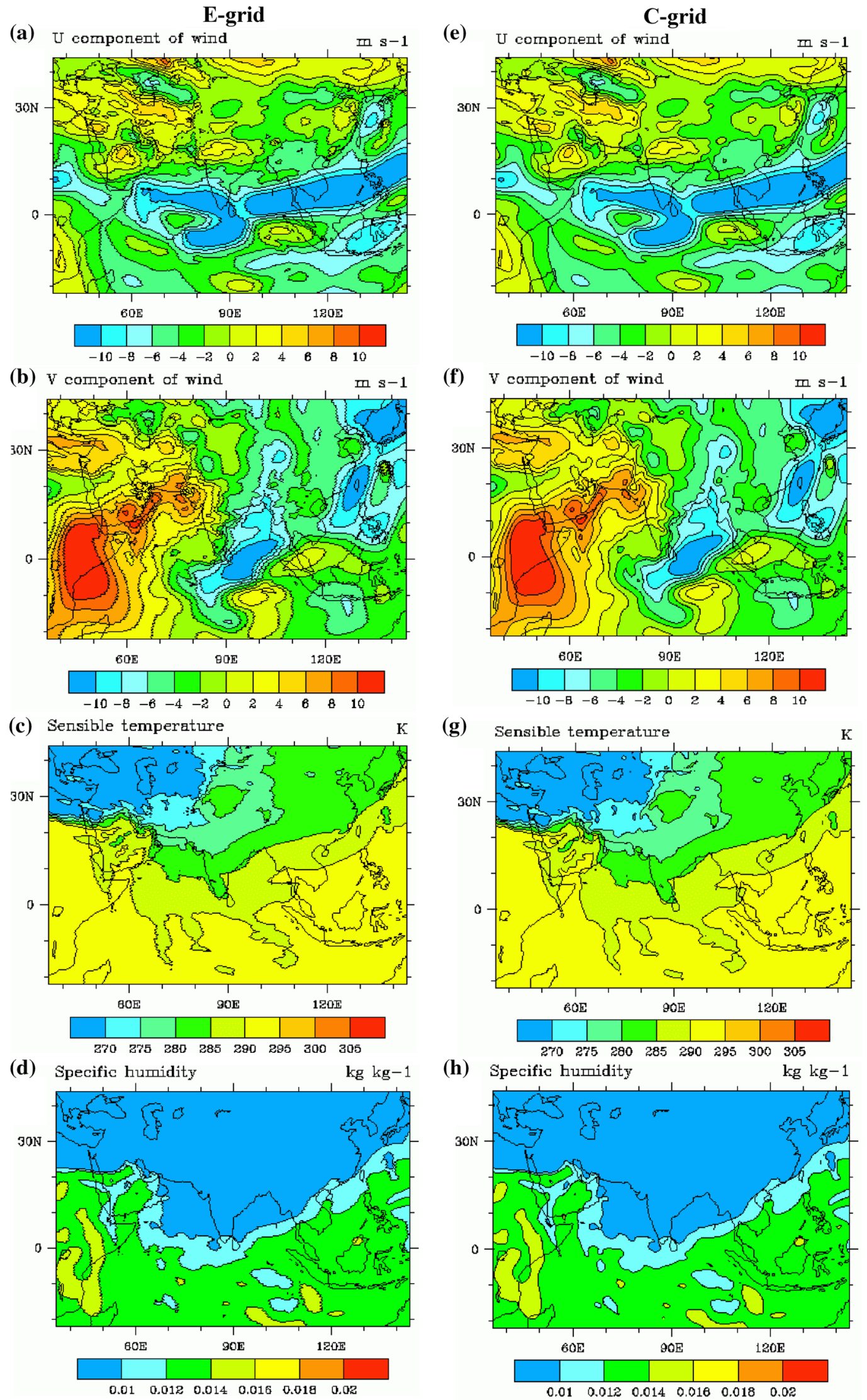

Figure 3. WRF-NMM fields at different grid structures. (a) Zonal wind (m/s), (b) meridional wind (m/s), (c) temperature $(\mathrm{K})$ and (d) specific humidity $\left(\mathrm{kg} \mathrm{kg}^{-1}\right)$ with Arakawa-E grid. (e-f) is same as (a-d), but with Arakawa-C grid structure. 

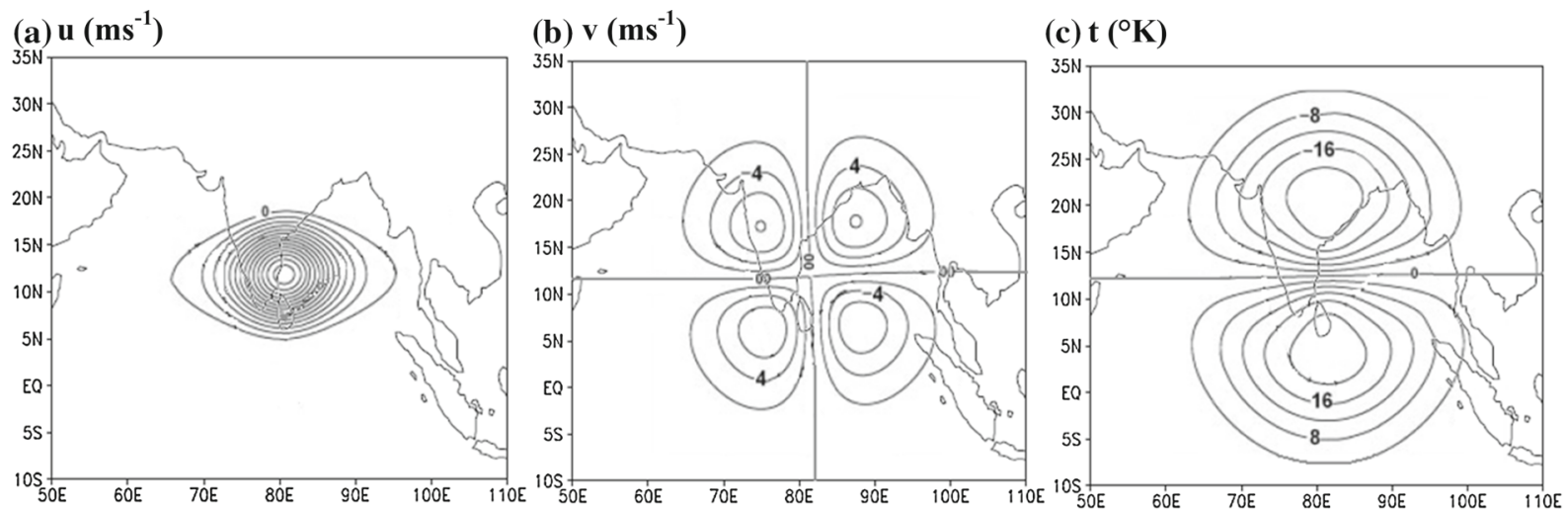

(d) $u\left(\mathrm{~ms}^{-1}\right)$

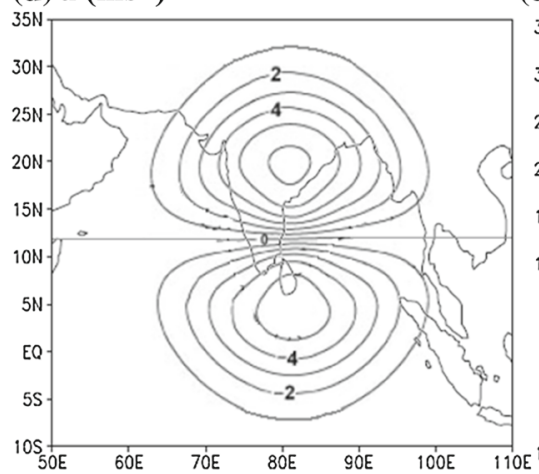

(e) $\mathbf{v}\left(\mathrm{ms}^{-1}\right)$

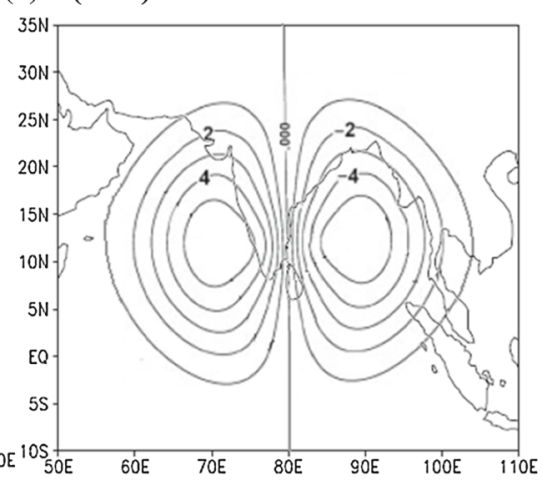

(f) $\mathbf{t}\left({ }^{\circ} \mathbf{K}\right)$

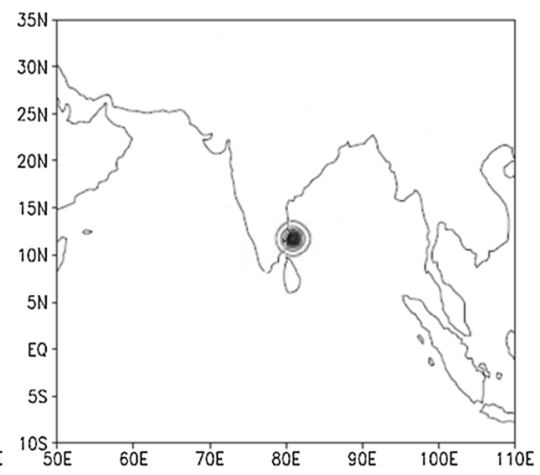

Figure 4. $(\mathbf{a}-\mathbf{c})$ are the response of the analysis increments with single perturbation of $1 \mathrm{~ms}^{-1}$ of $\mathrm{u}$-wind at the center of the domain $\left(11.8^{\circ} \mathrm{N}, 81.7^{\circ} \mathrm{E} ; 25\right.$ sigma level). (d-f) are the response of the in $\mathrm{u}$ - and $\mathrm{v}$-wind with single observation of $1 \mathrm{~K}$ temperature.

\subsection{Background error statistics}

Forecast (background) error covariances are a vital input to any modern data assimilation system. They influence the analysis fit to observations and also completely define the analysis response away from observations (Barker 2004). The background error covariance generation code gen_be has been updated successfully for WRF-NMM. In this section, the background error statistics generated by the NMC method from WRF-NMM model integration has been evaluated and presented.

Figure $5(\mathrm{a}, \mathrm{b}, \mathrm{c}$ and $\mathrm{d})$ represents the eigenvectors generated for psi, chi, temperature and relative humidity fields respectively with different modes. Here, we have plotted for five different modes for each of the control variable fields psi, chi, temperature and relative humidity which is coherent with the structures of the eigenvector. Figure 6(a, b, c and d) shows the eigenvalues for psi, chi, temperature and relative humidity which clearly shows that, at the lower model levels the eigenvalues are maximum and nearly by 20 th model level onwards, it tends to zero for psi and chi fields and nearly about 35th model level, it is zero for temperature and relative humidity. Figure 7 (a, b, c and d) are the length scales ( $\mathrm{km}$ ) of psi, chi, temperature and relative humidity, respectively. The length scale is a particular length or distance determined with the precision of one order (or a few orders) of magnitude. The length scale is particularly important because physical phenomena of different length scales cannot affect each other and are said to decouple. The decoupling of different length scales makes it possible to have a self-consistent theory that only describes the relevant length scales for a given problem. The maximum length scale has been achieved at the lowest model levels for psi, chi, and temperature, but in case of relative humidity, it is more at the top of the model level.

The successful implementation of the extended WRFDA system for severe weather system over Indian region is presented in the following subsection.

\subsection{Implementation of extended assimilation system}

The extended WRF variational assimilation system is implemented for the forecast of a few tropical cyclones developed over Bay of Bengal (BoB). 
(a)

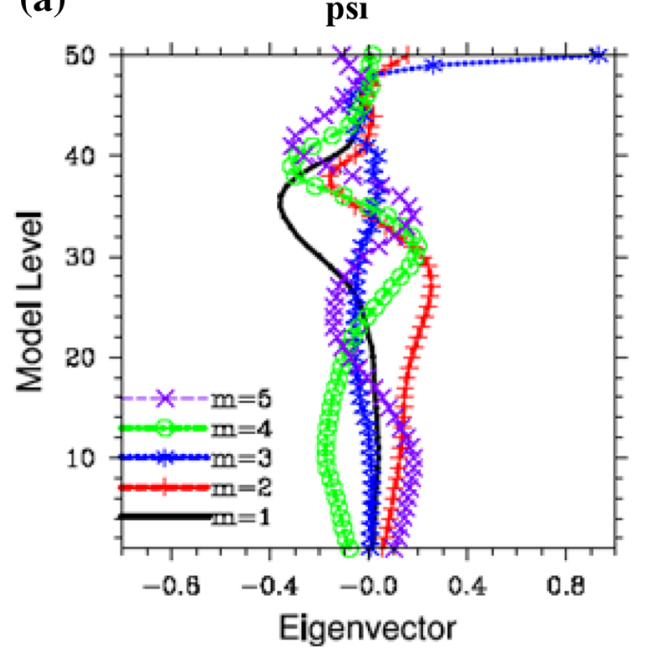

(c)

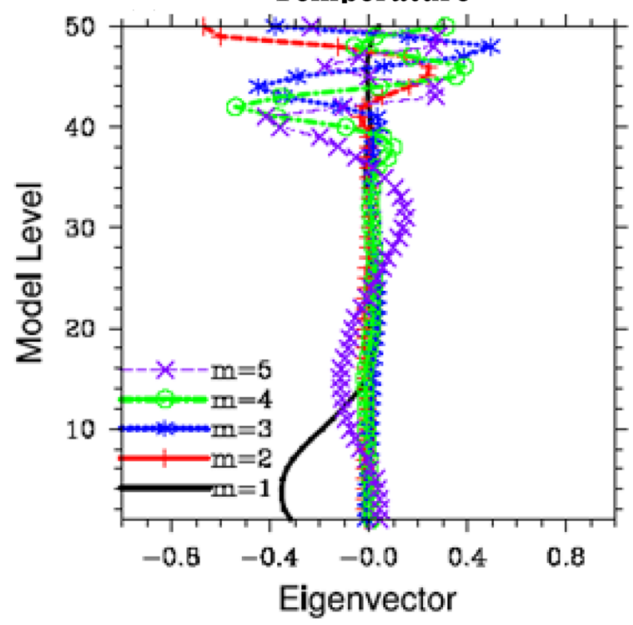

(b)
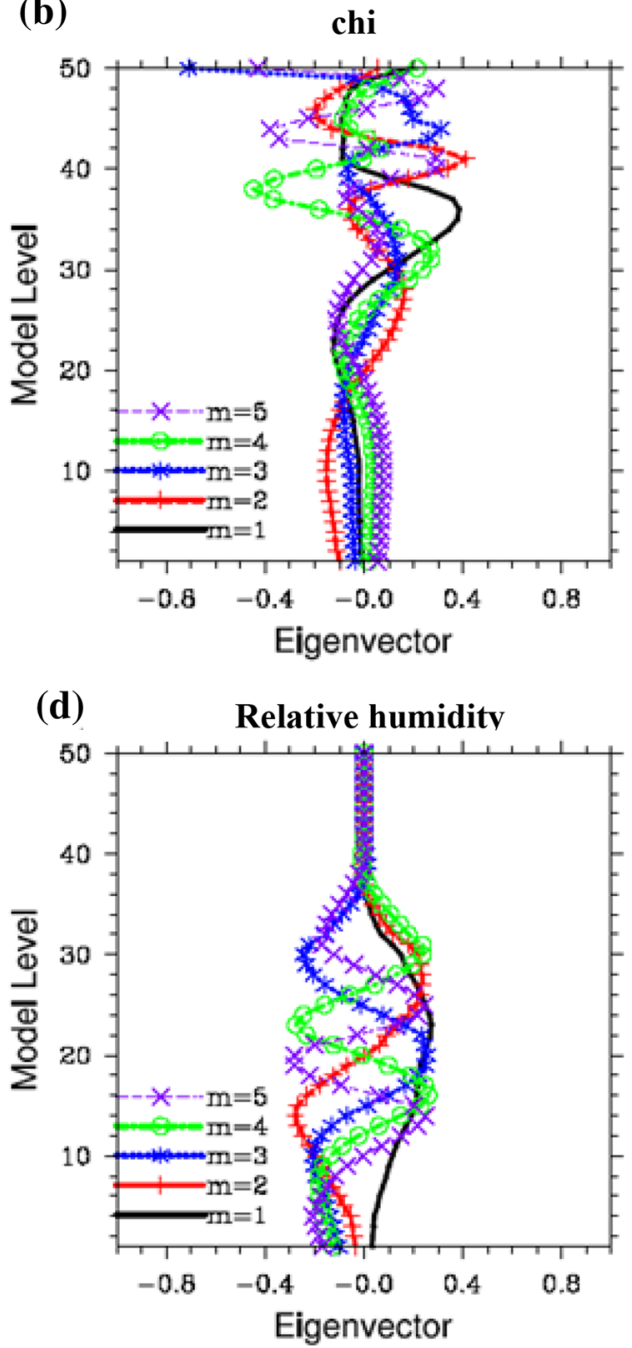

Figure 5. Eigenvectors generated for (a) psi, (b) chi, (c) temperature and (d) relative humidity with different modes.

The BoB contributes a very limited number of cyclones, i.e., about $5 \%$ of the global annual TCs (Mohanty et al. 2010); however, these are highly destructive. Also, the cyclones that are formed over BoB can move in three directions such as (i) northward: the straight movement (ii) westnorthwestward or northwestward as of their usual movement in Northern Hemisphere and (iii) eastward after re-curvature. Thus, in the present study, we analyzed three tropical cyclones namely Nargis (27 April-3 May 2008), Aila (23-26 May 2009) and Jal (4-8 November 2010) formed over the BoB and moved in three different directions such as east-, north- and west-ward, respectively.

These three tropical cyclones with unique characteristics (movement of the cyclones as mentioned above) are initialized with a total of 24 different initial conditions (eight initial conditions for Nargis; seven initial conditions for Aila and nine initial conditions for Jal). Two sets of numerical experiments are carried out for all the cases. In the first experiment, i.e., in the control experiment (CNTL), the initial and lateral boundary conditions to the model integration are taken from the National Center for Environmenetal Prediction (NCEP) Global Forecast System (GFS) analyses and forecast products. The GFS analyses and forecast products are available in $0.5^{\circ} \times 0.5^{\circ}$ (lat. $\times$ long.) horizontal resolution with 64 vertical levels. Since the forecast is carried out for regional domains for less than a week period, the lower boundary conditions are not updated in later analysis time. The surface conditions, both, over the land and ocean are taken care in the land surface boundary conditions. It has been hypothesized that the inclusion of observational data may improve the initial condition for model integration. Thus, in the second experiment, i.e., with data 

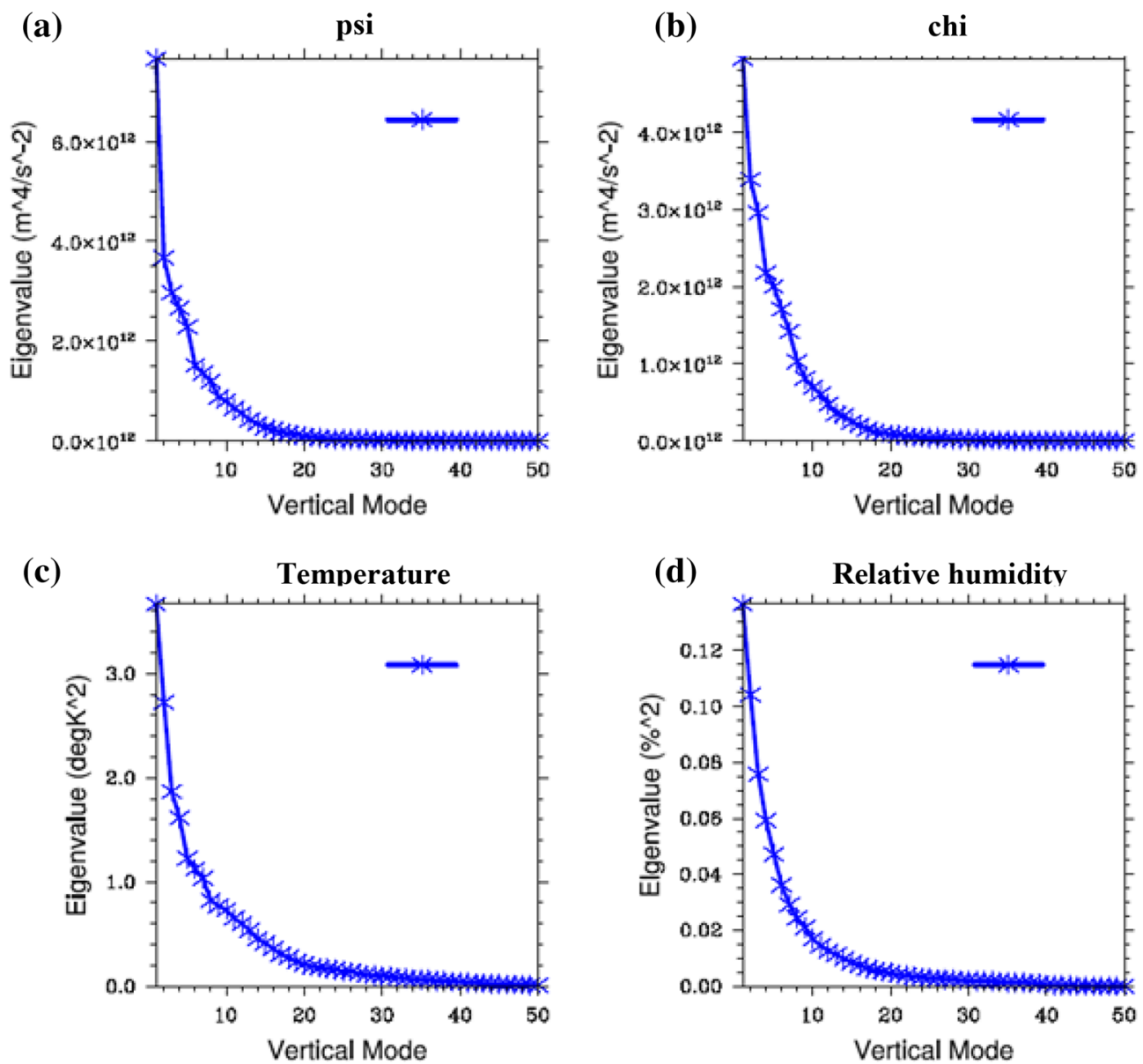

Figure 6. Eigenvalues generated for (a) psi, (b) chi, (c) temperature and (d) relative humidity corresponding to vertical modes.

assimilation (DA), the conventional and non-conventional observations available from Global Telecommunication System (GTS) and scatterometer wind fields are assimilated at the initial time of model integration, considering GFS as the background fields. The observational datasets include the data from different platforms like Synop, Sound, Metar, Pilot, Buoy, Ships, Airep, Geoamv and Qscat. These datasets have undergone with various quality control checks. It includes gross check, gross pressure/height consistent check, vertical consistent check and discard of the data in both spatial (horizontal and vertical) and temporal domain of the model integration. The model integration time is fixed based on the life period of each cyclone. In case of Nargis and Jal, the model is integrated up to $120 \mathrm{hr}$, whereas TC Aila is integrated up to $72 \mathrm{hr}$. The experimental domain of the WRF-NMM model is fixed to $9 \mathrm{~km}$ horizontal resolution with 51 vertical levels. The details of WRFNMM model configuration used in this study are presented in table 1 and the numerical experiments are provided in table 2. The results are broadly classified in two sub-sections, i.e., (i) improvement in the initial position and intensity and (ii) enhancement in the model simulated track, intensity and structure of the TCs over BoB.

\subsubsection{Initial position and intensity of the cyclone}

The variation in initial position, intensity, and structure of the cyclones examined before (CNTL) and after assimilation (DA) are described in this section. For this purpose, the initial positional error $(\mathrm{km})$ and intensity error in terms of central sea level pressure (CSLP in $\mathrm{hPa}$ ) and maximum sustainable wind (MSW in $\mathrm{m} / \mathrm{s}$ ) are evaluated for all the 24 cases individually. Figure 8(a) demonstrates the mean initial positional errors for each cyclone, i.e., Nargis, Aila and Jal with respect to the best track position obtained from India Meteorological Department (IMD) (RSMC 2009, 2010, 2011). The GFS analysis which is used to run CNTL experiment shows higher positional 

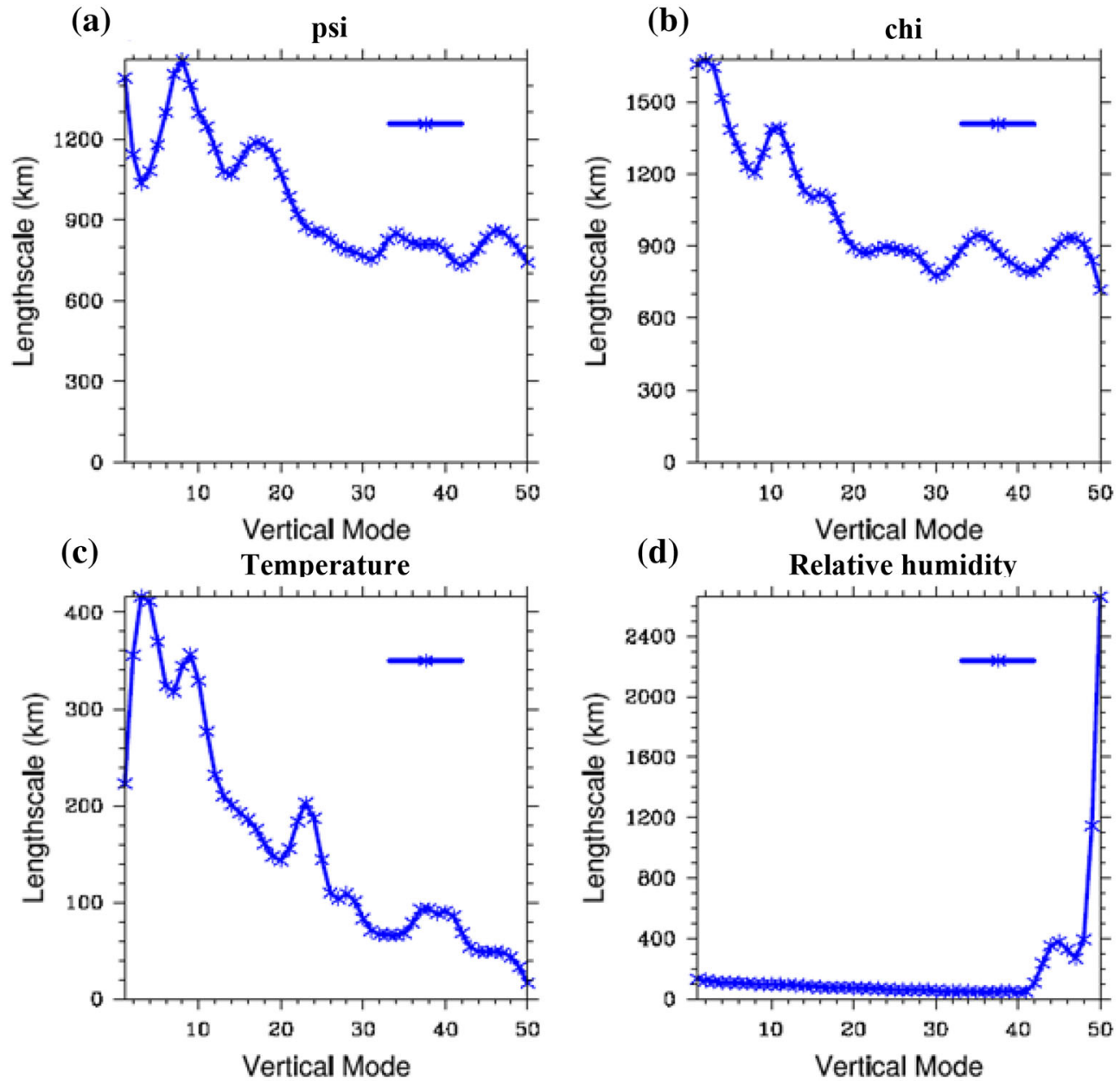

Figure 7. Length scale generated for (a) psi, (b) chi, (c) temperature and (d) relative humidity corresponding to vertical modes.

error in all the cases than the DA analysis. The mean initial positional error has been reduced by 33, 19 and 49\% for Nargis, Aila and Jal cases, respectively. The mean of all the 24 cases shows an improvement of $33 \%$ with DA analysis than that of GFS analysis. Figure 8(b and c) represents the mean intensity error in terms of CSLP $(\mathrm{hPa})$ and MSW $(\mathrm{m} / \mathrm{s})$, respectively. It is noticed that Nargis shows higher intensity error than that of Aila and Jal cyclones. However, in all the cases, the error reduces in DA analysis than that of GFS analysis. The mean improvement of 19 and $27 \%$ is estimated for CSLP and MSW, respectively.

\subsubsection{Simulated track, intensity and structure of cyclones}

The model-simulated track, intensity and structure of the cyclones at subsequent forecast time are presented in this sub-section.

\subsubsection{Track}

Figure $9(\mathrm{a}$ and $\mathrm{b})$ represents model-simulated tracks for the cyclone Nargis with GFS analysis (CNTL) and with high-resolution mesoscale data assimilation (DA) experiments at different initial conditions, respectively. Both the experiments simulated the movements of the storm towards Myanmar coast from each initial condition. However, the widespread tracks of about $400 \mathrm{~km}$ in latitudinal direction are seen in CNTL which reduces by nearly $250 \mathrm{~km}$ in DA experiments. The vector displacement errors (VDEs) are evaluated as provided in equation (2) in $12 \mathrm{hr}$ for each case and the mean VDEs from both the experiments are shown in figure $9(\mathrm{c})$.

$$
\mathrm{VDE}=\operatorname{SQRT}\left[\left(\mathrm{X}_{1}-\mathrm{X}_{2}\right)^{2}+\left(\mathrm{Y}_{1}-\mathrm{Y}_{2}\right)^{2}\right]
$$

where $\mathrm{X}_{1}$ and $\mathrm{X}_{2}$ are the longitudinal points for both observation and model forecast track position, and $Y_{1}$ and $Y_{2}$ are the latitudinal points for both 
Table 1. Details of the WRF-NMM model configurations used in the present study.

\begin{tabular}{ll}
\hline Model & NCEP mesoscale model WRF-NMM V3.0 \\
\hline Dynamics & $\begin{array}{c}\text { Non-hydrostatic with terrain following hybrid } \\
\text { pressure sigma vertical co-ordinate } \\
\text { Rotated lat.-long. }\end{array}$ \\
Map projection & $9 \mathrm{~km}$ \\
Resolution & 51 \\
No. of vertical levels & Arakawa E-grid \\
Horizontal grid scheme & Horizontal: forward-backward scheme vertical: \\
Time integration scheme & implicit scheme \\
& NCEP/NCAR GFS forecast \\
Lateral boundary condition & Long wave: GFDL short wave: GFDL \\
Radiation scheme & Yonsei University (YSU) \\
Planetary boundary layer & \\
parameterization schemes & Simplified Arakawa Schubert \\
Cumulus parameterization & \\
schemes & NMM \\
Land surface physics & Ferrier \\
Microphysics & GFS analysis $\left(0.5^{\circ} \times 0.5^{\circ}\right)$ \\
Initial and lateral boundary & \\
condition & \\
\hline
\end{tabular}

Table 2. Details of the numerical experiments carried out in the present study.

\begin{tabular}{|c|c|c|c|}
\hline $\begin{array}{l}\text { TC name } \\
\text { (intensity) }\end{array}$ & $\begin{array}{c}\text { Forecast dates } \\
\text { (initial condition) }\end{array}$ & $\begin{array}{c}\text { Forecast lengths } \\
(\mathrm{hr})\end{array}$ & No. of cases \\
\hline \multirow[t]{8}{*}{ Nargis (VSCS) } & 0000 UTC 28 April 2008 & 120 & 8 \\
\hline & 1200 UTC 28 April 2008 & 120 & \\
\hline & 0000 UTC 29 April 2008 & 120 & \\
\hline & 1200 UTC 29 April 2008 & 120 & \\
\hline & 0000 UTC 30 April 2008 & 96 & \\
\hline & 1200 UTC 30 April 2008 & 96 & \\
\hline & 0000 UTC 01 May 2008 & 72 & \\
\hline & 1200 UTC 01 May 2008 & 72 & \\
\hline \multirow[t]{7}{*}{ Aila (SCS) } & 0000 UTC 22 May 2009 & 72 & 7 \\
\hline & 1200 UTC 22 May 2009 & 72 & \\
\hline & 0000 UTC 23 May 2009 & 72 & \\
\hline & 1200 UTC 23 May 2009 & 72 & \\
\hline & 0000 UTC 24 May 2009 & 48 & \\
\hline & 1200 UTC 24 May 2009 & 48 & \\
\hline & 0000 UTC 25 May 2009 & 48 & \\
\hline \multirow[t]{10}{*}{ Jal (SCS) } & 0000 UTC 03 November 2010 & 120 & 9 \\
\hline & 1200 UTC 03 November 2010 & 120 & \\
\hline & 0000 UTC 04 November 2010 & 96 & \\
\hline & 1200 UTC 04 November 2010 & 96 & \\
\hline & 0000 UTC 05 November 2010 & 72 & \\
\hline & 1200 UTC 05 November 2010 & 72 & \\
\hline & 0000 UTC 06 November 2010 & 72 & \\
\hline & 1200 UTC 06 November 2010 & 48 & \\
\hline & 0000 UTC 07 November 2010 & 48 & \\
\hline & Total number of cases & & 24 \\
\hline
\end{tabular}

observation and model forecast track position. These observed and forecasted points are converted to radians and then into kilometer.
Within the uncertainty of observations, DA simulated tracks are better than CNTL. This may be attributed due to the improvement in $\mathrm{TC}$ 

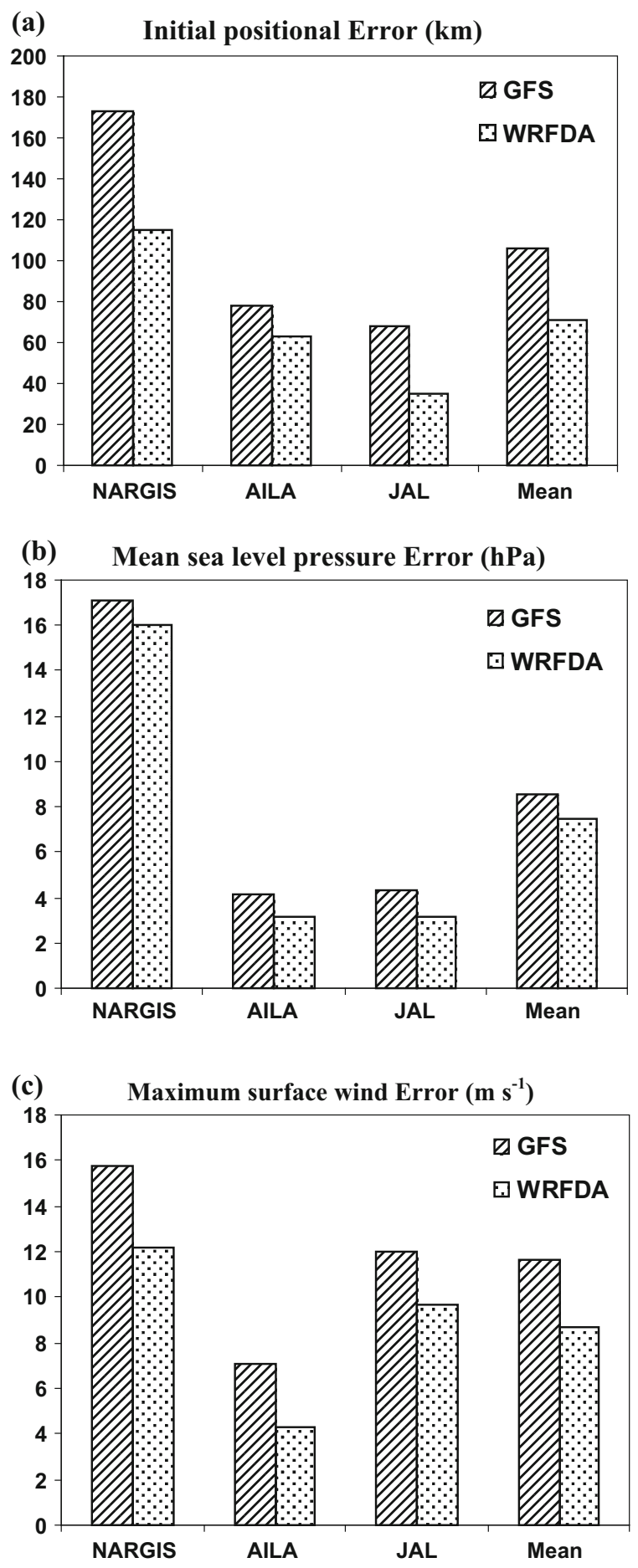

Figure 8. (a) Mean initial positional error (km), (b) mean sea level pressure error $(\mathrm{hPa})$, and (c) mean surface wind error $\left(\mathrm{ms}^{-1}\right)$ in the GFS and WRFDA analyses for the best-fit observations as obtained from India Meteorological Department.

position at the initial time of the model integration. The average VDEs in track forecast decrease up to $48 \mathrm{hr}$ and increase from $60 \mathrm{hr}$ onwards. However, the average VDEs are confined within $250 \mathrm{~km}$ up to $96 \mathrm{hr}$ and reduce significantly with DA experiments than CNTL.

Figure 10(a and b) depicts the track forecasts for the cyclone Aila from both CNTL and DA experiments. It is a northward moving cyclone and both the analyses predict the movement of the cyclone with reasonable accuracy. However, the DA experiments with different initial conditions show less error than the CNTL experiments. Specifically, the track forecast with 0000 UTC 24 May 2009 initial condition represents less VDEs and less landfall error with both CNTL and DA experiments. It may be noted that the DA experiment has less VDEs and landfall errors than the CNTL. Figure 10(c) presents the average VDEs up to $96 \mathrm{hr}$. At the initial time, the DA experiments show less average VDEs than the CNTL. It is observed that the average VDEs are improved by $14-31 \%$ range in $96 \mathrm{hr}$ track forecast.

Figure 11(a and b) represents the track forecast for the cyclone Jal from both CNTL and DA experiments, respectively. The forecast of Jal cyclone shows more error than Nargis and Aila case. The CNTL results have a larger spread of an about $500 \mathrm{~km}$ with different initial conditions. The track forecast for 0000 UTC 07 November 2011 initial condition has less VDEs and landfall errors than other initial conditions. Figure 11(c) represents the average VDEs for up to $96 \mathrm{hr}$ forecast from different initial conditions. Though the initial positional errors are quite less in both CNTL and DA experiments, the errors increase with forecast length, but the DA experiments show less error than CNTL.

The mean VDEs and landfall errors (LEs) for all the 24 cases are evaluated and presented in table 3 . The mean improvement in the range of $19-33 \%$ is noticed in DA experiments than the CNTL. The LEs $(\mathrm{km})$ are evaluated with respect to the forecast hours prior to the landfall of each cyclone. The mean LE prior to $96 \mathrm{hr}$ is about $286 \mathrm{~km}$ with CNTL experiments and reduces to $212 \mathrm{~km}$ with DA experiments. The mean LE is improved by $27 \%$ in DA experiments.

\subsubsection{Intensity}

The intensity forecast of the cyclones with model integration has been evaluated in terms of CSLP $(\mathrm{hPa})$ and $\mathrm{MSW}(\mathrm{m} / \mathrm{s})$. Figure 12(a and b) illustrates the time evolution of mean intensity in terms of CSLP $(\mathrm{hPa})$ and $\mathrm{MSW}(\mathrm{m} / \mathrm{s})$, respectively, for the cyclone Nargis. The observed CSLP as obtained from India Meteorological Department 
(a) Tracks of Nargis: CNTL

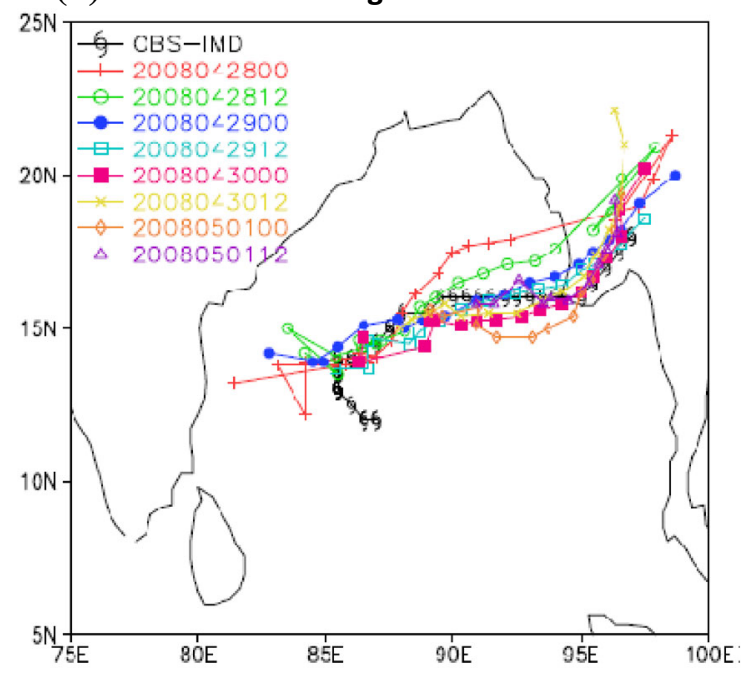

(b) Tracks of Nargis: DA

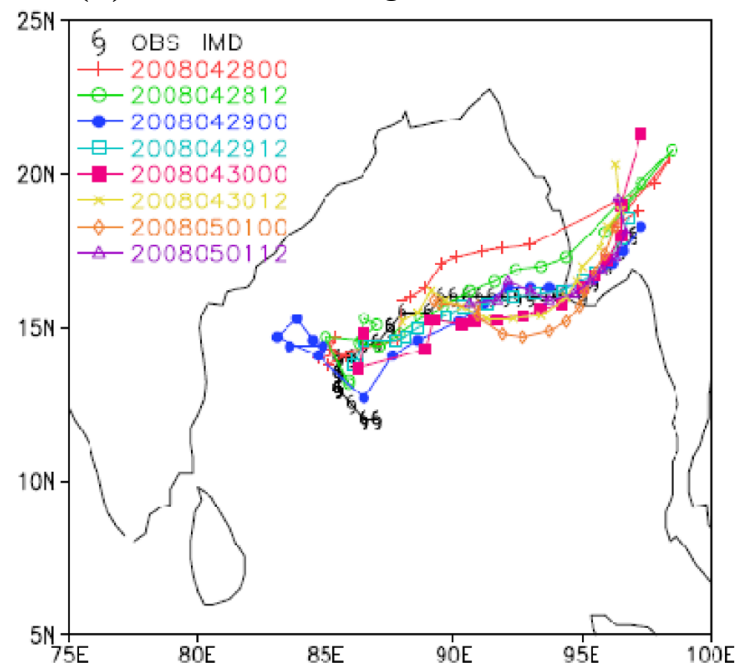

(c) Mean vector displacement error (km): Nargis

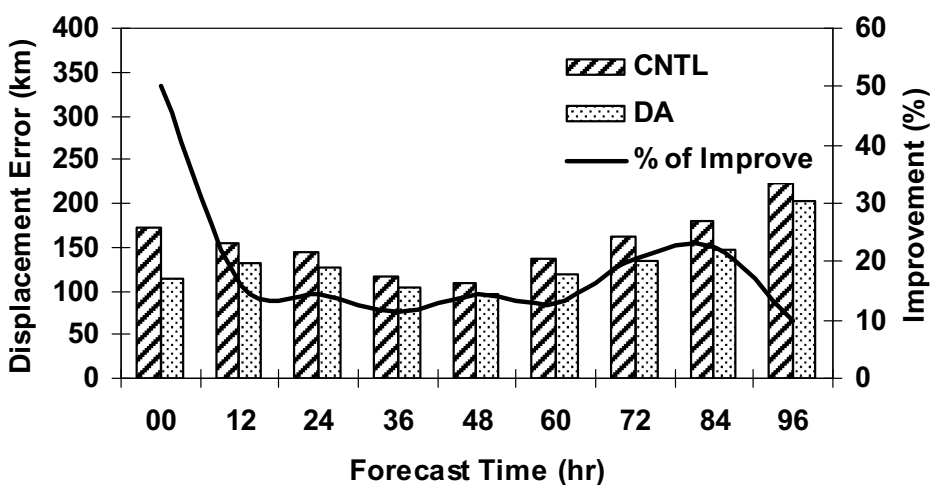

Figure 9. Tracks with different initial conditions with (a) control simulation (CNTL), (b) data assimilation (DA), and (c) mean vector displacement errors $(\mathrm{km})$ for both the CNTL and DA experiments for cyclone Nargis.

(IMD) is also provided along with the model forecasts. The observed minimum CSLP was $962 \mathrm{hPa}$ valid at $0600 \mathrm{UTC} 02$ May 2008, and model could simulate the maximum intensity of $961 \mathrm{hPa}$ valid at the same time with the DA experiment. It is noticed that both CNTL and DA experiments capture the peak intensity of the storm with reasonable accuracy. The time of peak intensity is also well captured with both the experiments. The intensification and dissipation of the storm are also well simulated by the model. Similarly, figure 12 (c and d) depicts the mean intensity forecast for cyclone Aila. The model overestimated the intensity forecast in both CNTL and DA experiments. The minimum CSLP was $968 \mathrm{hPa}$ valid at 0900 UTC 25 May 2009. However, the model simulates the peak intensity prior to $3 \mathrm{hr}$ of the actual. Also, a sharp increase in MSW is noticed, but before $3 \mathrm{hr}$ of the actual observation. It is seen that the model overestimated the intensity of Aila with a prior of $3 \mathrm{hr}$ in peak intensity period. Figure $12(\mathrm{e}$ and $\mathrm{f}$ ) illustrates the mean intensity forecast of cyclone Jal from both CNTL and DA experiments. The observed minimum CSLP was $988 \mathrm{hPa}$ valid at $1200 \mathrm{UTC}$ 06 November 2010. However, both the experiments simulate lower CSLP and higher MSW values than the observed value. The observed MSW is $31 \mathrm{~m} / \mathrm{s}$ valid at 1200 UTC 06 November 2010. The CNTL and DA experiments predicted the MSW of 49 and $45 \mathrm{~m} / \mathrm{s}$, respectively valid at the same time.

The error in CSLP $(\mathrm{hPa})$ and $\mathrm{MSW}(\mathrm{m} / \mathrm{s})$ are evaluated through RMSE. Figure 13(a, b), (c, d) and $(\mathrm{e}, \mathrm{f})$ represent the RMSEs of CSLP (hPa) and MSW (m/s) for Nargis, Aila and Jal, respectively. From all the three cyclones, Aila cyclone provides higher intensity error than the other two cyclones. This may be due to the prior intensification and dissipation of the storm. In case 
(a) Tracks of Aila: CNTL

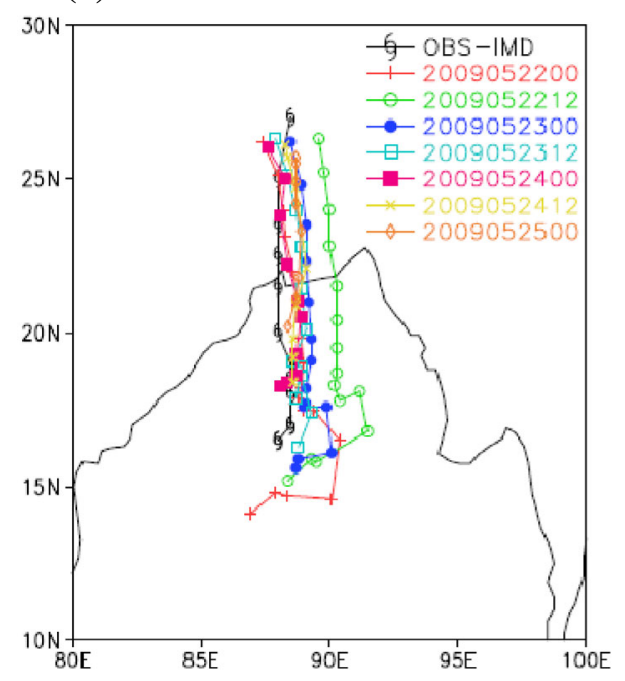

(b)

Tracks of Aila: DA

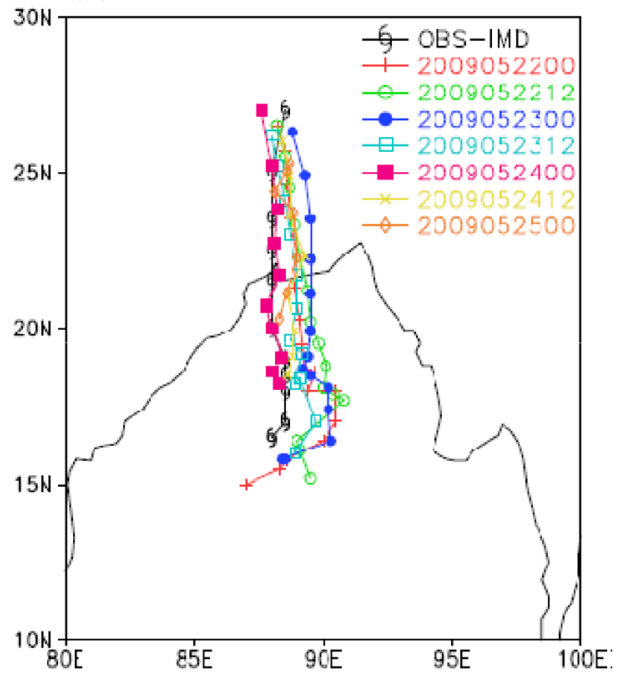

(c) Mean vector displacement error (km): Aila

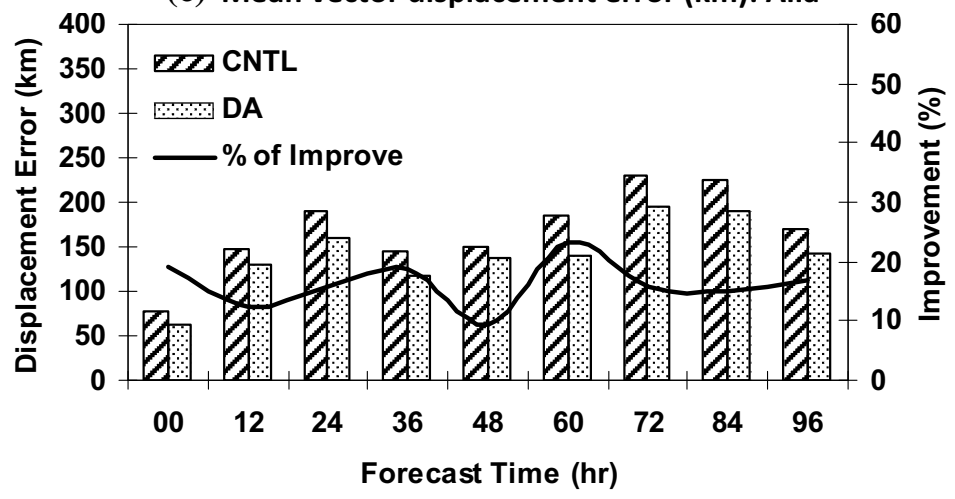

Figure 10. Tracks with different initial conditions with (a) control simulation (CNTL), (b) data assimilation (DA), and (c) mean vector displacement errors $(\mathrm{km})$ for both the CNTL and DA experiments for the cyclone Aila.

of Nargis, the RMSE reduces significantly in DA experiments than the CNTL at each forecast hour except for $48 \mathrm{hr}$ forecast. The mean of all the cases is presented in figure $13(\mathrm{~g}$ and $\mathrm{h}$ ) which clearly indicates the improvement in DA experiments than the CNTL, though the impact is not very significant as in case of track forecast.

Hence, it is to be noted that the DA experiments improve the track and intensity forecast for all the cyclones Nargis, Aila and Jal used in the present study. The improvement in the model forecast with DA experiments has been further investigated in analyzing the inner core structure of the cyclone.

\subsubsection{Structure}

It has been attempted to study the inner core structure of all the three cyclones Nargis, Aila and
Jal (not all shown) from the model forecasts. For this purpose, the longitudinal variation of horizontal wind $(\mathrm{m} / \mathrm{s})$, pressure vertical velocity $(\mathrm{Pa} / \mathrm{s})$ and vorticity $\left(\times 10^{-5}\right)$ fields are presented at the peak intensity of the cyclone.

Figure 14(a and b) demonstrates the longitudinal variation of horizontal wind field $(\mathrm{m} / \mathrm{s})$ for the cyclone Nargis with CNTL and DA experiments respectively valid at 0900 UTC 02 May 2008. The maximum horizontal wind is simulated in the lower atmosphere with both the experiments. The horizontal wind of $50 \mathrm{~m} / \mathrm{s}$ is simulated with the CNTL experiment, whereas the DA experiment simulates $55 \mathrm{~m} / \mathrm{s}$. The calm core of the cyclone is well simulated with the DA experiment. The westerly wind is found to be stronger in both the experiments. Figure 14(c and d) represents the vertical cross-section of pressure vertical velocity valid at the intense period of the cyclone Nargis. The strong 
(a) Tracks of Jal: CNTL

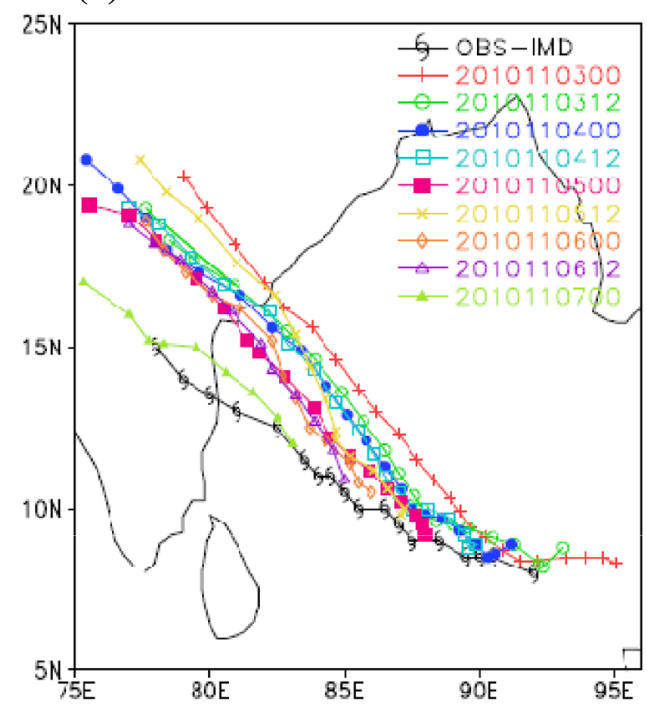

(c) Mean vector displacement error (km): Jal

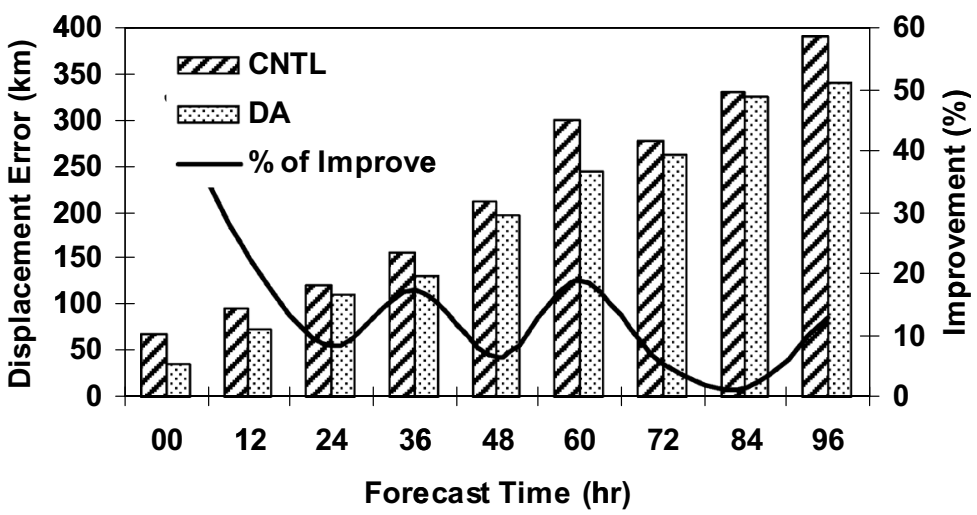

(b) Tracks of Jal: DA

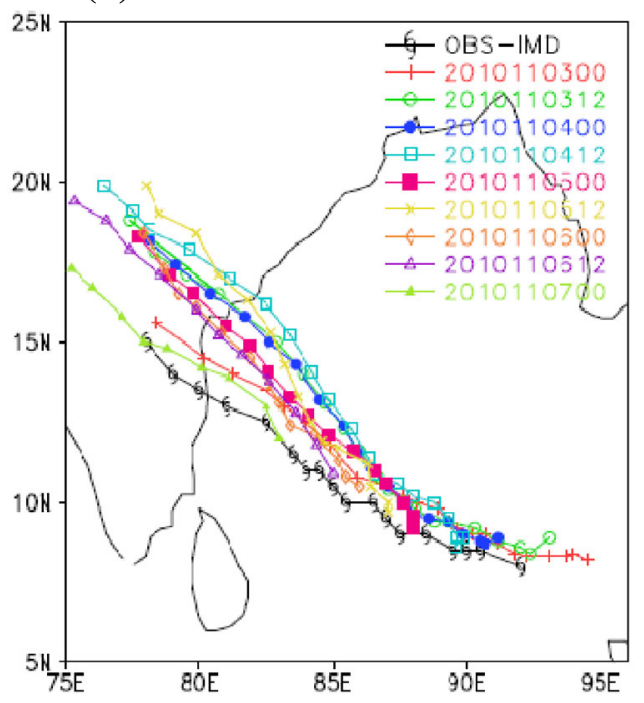

(d) Mean landfall error $(\mathbf{k m})$

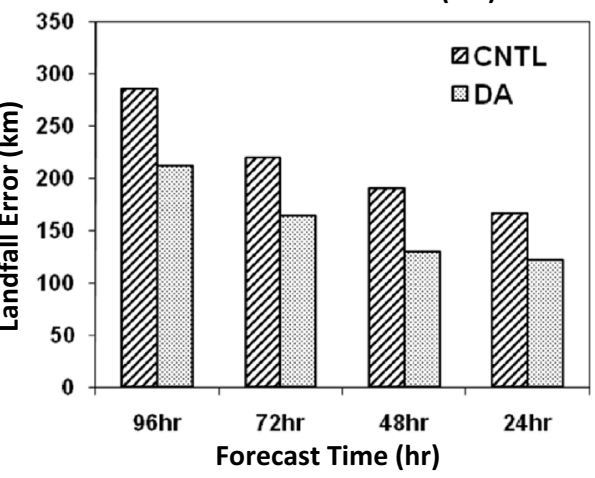

Figure 11. Tracks with different initial conditions with (a) control (CNTL), (b) data assimilation (DA), (c) mean vector displacement errors $(\mathrm{km})$ for both the CNTL and DA experiments for cyclone Jal and (d) mean landfall error w.r.t. forecast lead time for all the cases with CNTL and DA experiments.

Table 3. Mean vector displacement error (VDE; km) and landfall errors (LE; $\mathrm{km})$ in CNTL and DA experiments and improvements in DA experiment (\%).

\begin{tabular}{|c|c|c|c|c|c|c|}
\hline \multirow[b]{2}{*}{ Forecast hours (hr) } & \multicolumn{2}{|c|}{$\begin{array}{c}\text { Vector } \\
\text { displacement } \\
\text { error (VDE; km) }\end{array}$} & \multirow[b]{2}{*}{ Improvements in VDE (\%) } & \multicolumn{2}{|c|}{$\begin{array}{l}\text { Landfall error } \\
(\mathrm{LE} ; \mathrm{km}) \text { in } \\
\text { forecast days }\end{array}$} & \multirow[b]{2}{*}{ Improvements in LE (\%) } \\
\hline & CNTL & DA & & CNTL & DA & \\
\hline 00 & 106 & 71 & 33 & & & \\
\hline 12 & 132 & 91 & 31 & & & \\
\hline 24 & 151 & 102 & 33 & 167 & 123 & 26 \\
\hline 36 & 159 & 117 & 27 & & & \\
\hline 48 & 177 & 123 & 31 & 191 & 130 & 32 \\
\hline 60 & 206 & 148 & 28 & & & \\
\hline 72 & 224 & 157 & 30 & 220 & 165 & 25 \\
\hline 84 & 245 & 198 & 19 & & & \\
\hline 96 & 261 & 208 & 20 & 286 & 212 & 26 \\
\hline Mean & 185 & 135 & 28 & 216 & 158 & 27 \\
\hline
\end{tabular}


(a) CSLP (hPa) for cyclone Nargis

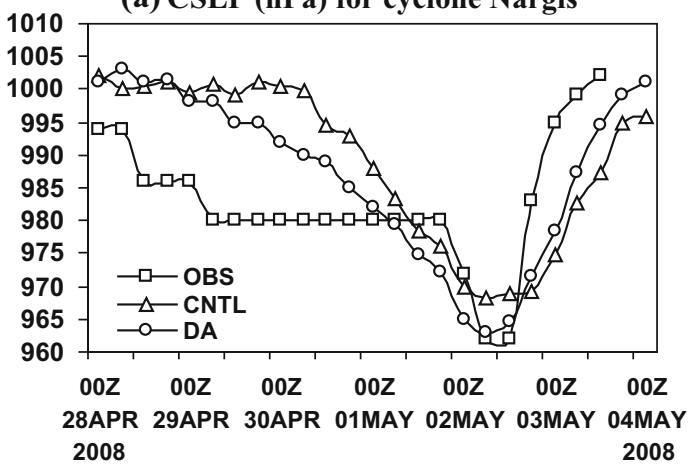

(c) CSLP (hPa) for cyclone Aila

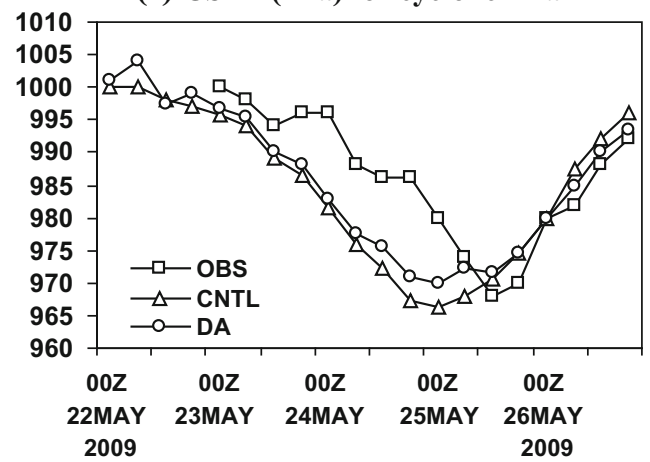

(e) CSLP (hPa) for cyclone Jal

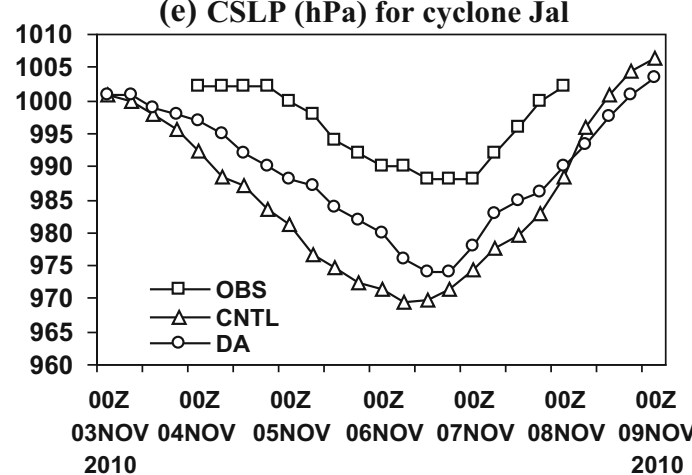

(b) Maximum surface wind $\left(\mathrm{m} \mathrm{s}^{-1}\right)$

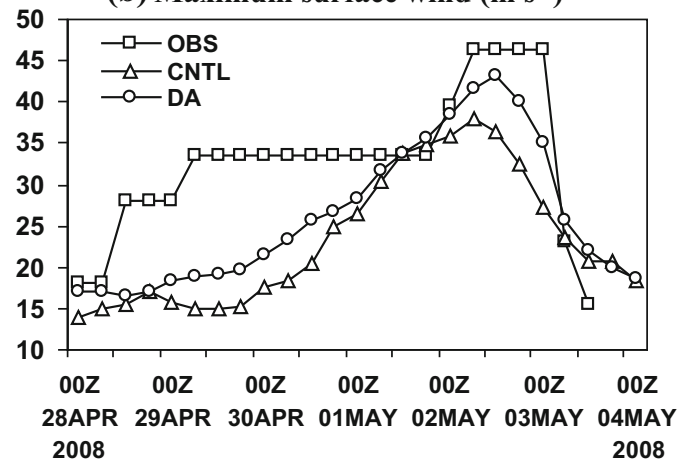

(d) Maximum surface wind ( $\left.\mathrm{m} \mathrm{s}^{-1}\right)$

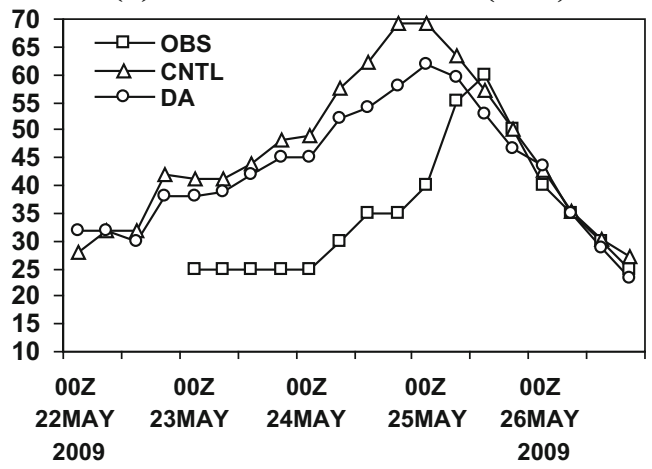

(f) Maximum surface wind ( $\left.\mathrm{m} \mathrm{s}^{-1}\right)$

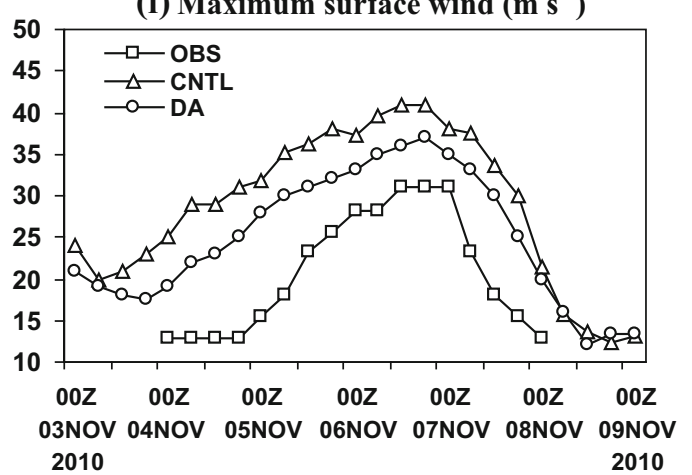

Figure 12. Mean intensity forecast: (a) minimum central sea level pressure (hPa) and (b) maximum surface wind (m $\mathrm{s}^{-1}$ ) for Nargis; $(\mathbf{c}-\mathbf{d})$ is same as $(\mathbf{a}-\mathbf{b})$, but for Aila and $(\mathbf{e}-\mathbf{f})$ is same as $(\mathbf{a}-\mathbf{b})$, but for Jal case.

updraft of $10 \mathrm{~m} / \mathrm{s}$ and downdraft of $8 \mathrm{~m} / \mathrm{s}$ is clearly noticed in DA experiment. The CNTL experiment exhibits updraft of $7 \mathrm{~m} / \mathrm{s}$ and downdraft of $9 \mathrm{~m} / \mathrm{s}$ valid at 0900 UTC 02 May 2008. The longitudinal variation of vorticity $\left(\times 10^{-5} \mathrm{~s}^{-1}\right)$ is presented in figure 14(e and f) with CNTL and DA experiments respectively valid at 0900 UTC 02 May 2008. The DA experiment shows higher vorticity value than the CNTL. The maximum vorticity of $210 \times 10^{-5} \mathrm{~s}^{-1}$ is simulated with CNTL, whereas the DA experiment simulates the maximum vorticity of $275 \times 10^{-5} \mathrm{~s}^{-1}$ at the most intense period of the storm. Similar type results are seen for Aila and Jal case also (figures not shown). In case of Aila, the DA experiment exhibits the maximum wind speed of $45 \mathrm{~m} / \mathrm{s}$, whereas the maxima of $35 \mathrm{~m} / \mathrm{s}$ with large east-west extent are noticed in CNTL. The maximum vorticity of $100 \times 10^{-5} \mathrm{~s}^{-1}$ is simulated in CNTL experiment with two maxima near 950 and $200 \mathrm{hPa}$ is noticed. The DA experiment simulates the maximum vorticity of about $115 \times 10^{-5} \mathrm{~s}^{-1}$ at the lower atmosphere. The strong updraft of about $7 \mathrm{~m} / \mathrm{s}$ and downdraft of about $6.5 \mathrm{~m} / \mathrm{s}$ are noticed in DA experiments. 
RMSE of CSLP (hPa)
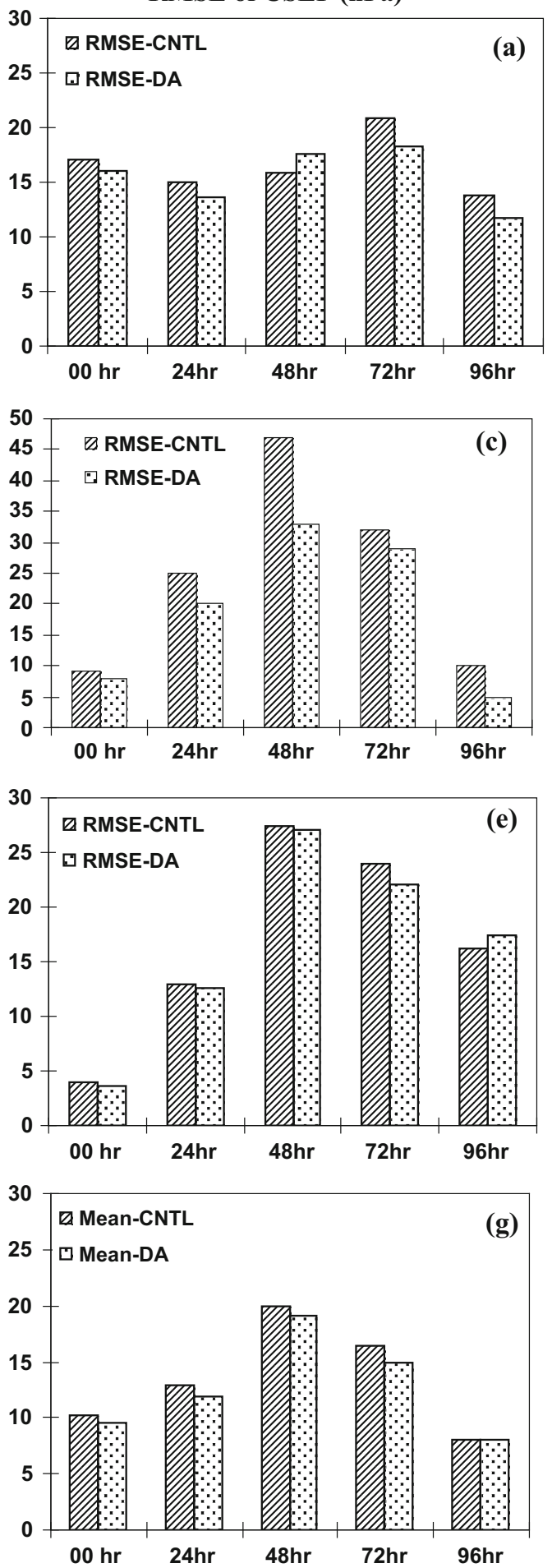

RMSE of MSW ( $\left.\mathrm{m} \mathrm{s}^{-1}\right)$
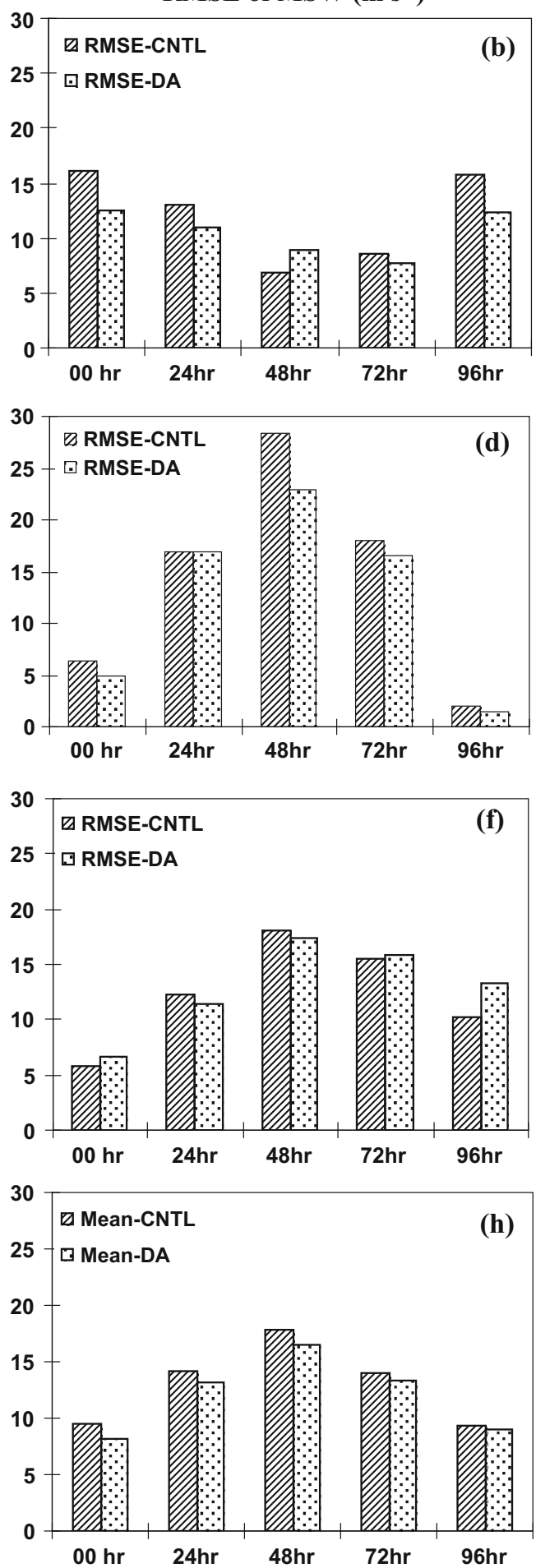

Figure 13. Root mean square error for the (a) minimum sea level pressure (hPa) and (b) maximum surface wind (m $\mathrm{s}^{-1}$ ) for Nargis. (c- $-\mathbf{d})$ is same as $(\mathbf{a}-\mathbf{b})$, but for Aila. $(\mathbf{e}-\mathbf{f})$ is same as $(\mathbf{a}-\mathbf{b})$, but for Jal, and $(\mathbf{g}-\mathbf{h})$ represents the mean of all cases.

In case of Jal, both the experiments simulate the calm core of the cyclone with the cyclonic wind at the eyewall. The CNTL experiment simulates the horizontal wind of about $45 \mathrm{~m} / \mathrm{s}$, whereas the DA experiment exhibits the wind speed of about
$55 \mathrm{~m} / \mathrm{s}$. The strong positive vorticity of the order of $(20-260) \times 10^{-5} \mathrm{~s}^{-1}$ is extended up to 100 and $200 \mathrm{hPa}$ in CNTL and DA experiments respectively. The maximum vorticity is clearly noticed in the lower atmosphere. The DA 
(a) Horizontal Wind $\left(\mathrm{m} \mathrm{s}^{-1}\right)$ : CNTL

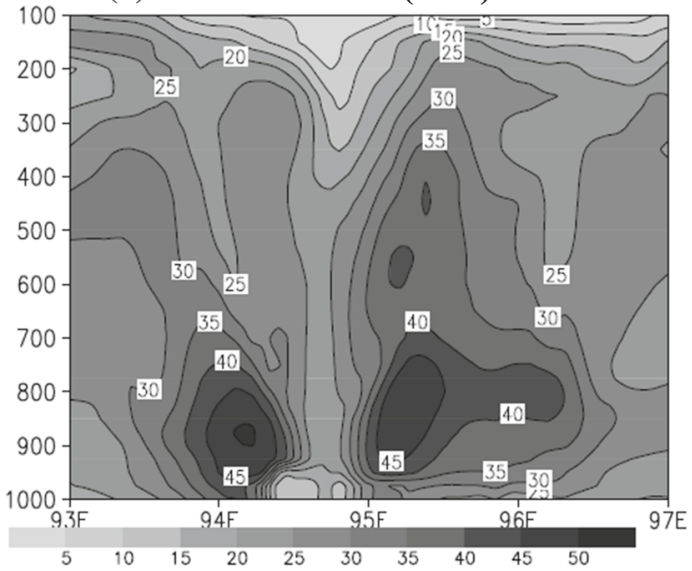

(c) Pressure vertical velocity $\left(\right.$ pa s $\left.^{-1}\right)$ : CNTL

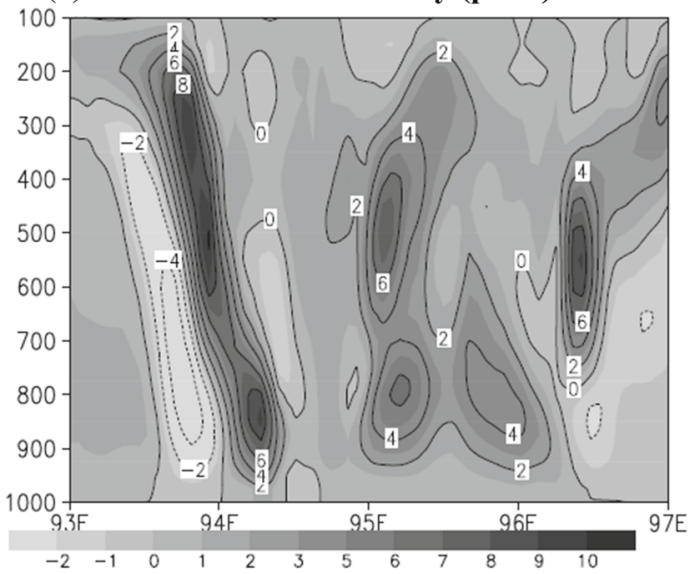

(e) Vorticity $\left(\times 10^{-5} \mathrm{~s}^{-1}\right)$ : CNTL

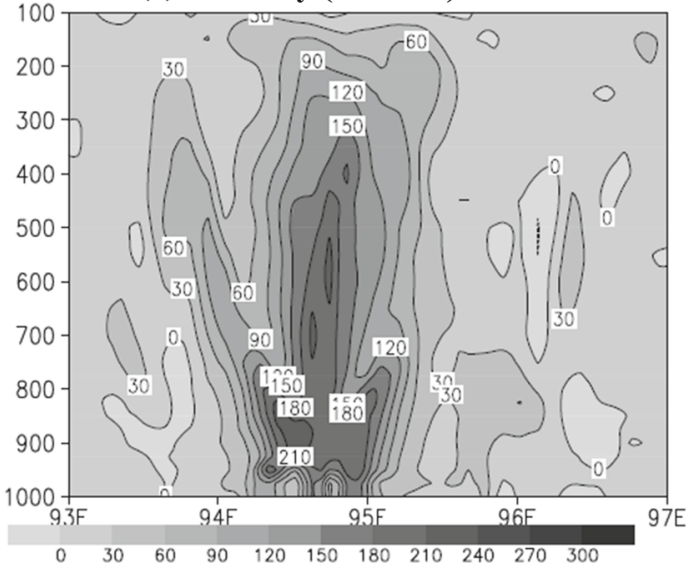

(b) Horizontal Wind $\left(\mathrm{m} \mathrm{s}^{-1}\right)$ : DA

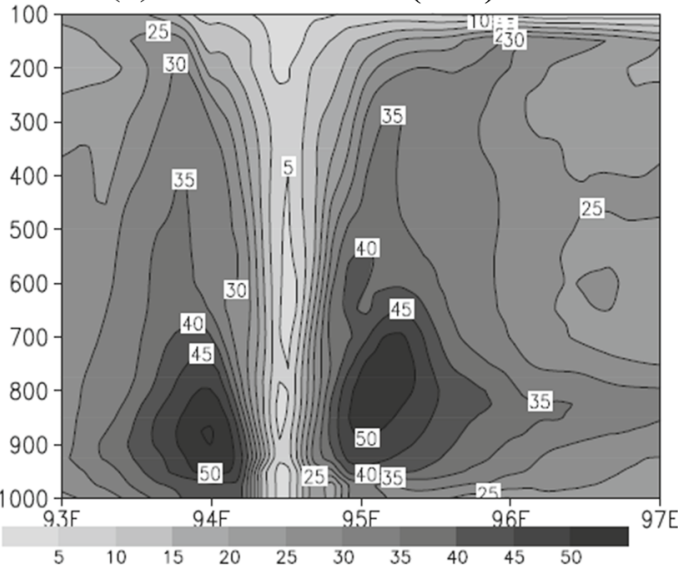

(d) Pressure vertical velocity $\left(\right.$ pa s $\left.^{-1}\right)$ : DA

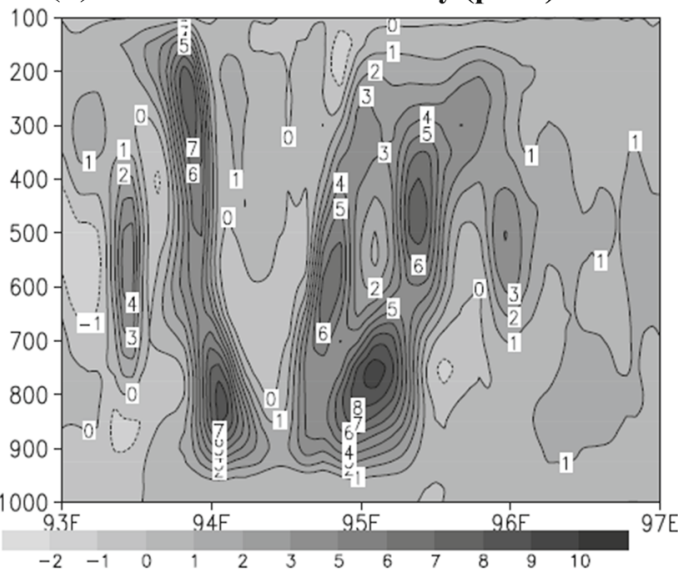

(f) Vorticity $\left(\times 10^{-5} \mathrm{~s}^{-1}\right)$ : DA

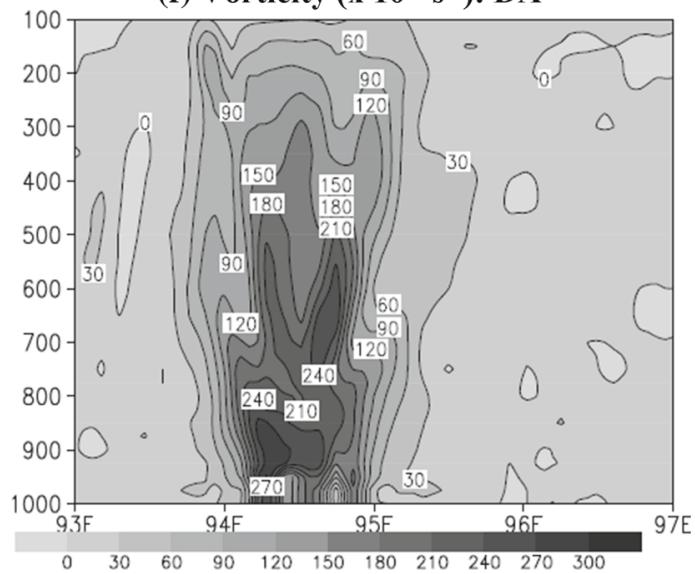

Figure 14. Longitudinal variation of $(\mathbf{a}-\mathbf{b})$ horizontal wind $\left(\mathrm{m} \mathrm{s}^{-1}\right),(\mathbf{c}-\mathbf{d})$ pressure vertical velocity $\left(\mathrm{Pa} \mathrm{s}^{-1}\right)$, and $(\mathbf{e}-\mathbf{f})$ vorticity $\left(\times 10^{-5} \mathrm{~s}^{-1}\right)$ from the control and data assimilation experiments, respectively for the cyclone Nargis valid at 0900 UTC 02 May 2008.

experiment simulates the intense storm with the strong updraft of about $15 \mathrm{~m} / \mathrm{s}$; however, strong updraft is extended from 850 to $300 \mathrm{hPa}$. Also, strong downdraft is clearly noticed on both sides of the eye of the cyclone. Similarly, the strong updraft of about $12 \mathrm{~m} / \mathrm{s}$ and downdraft of $12 \mathrm{~m} / \mathrm{s}$ are simulated with the CNTL experiment.

Hence, it is to be noted that in all the cases, the DA experiments well simulated the intensity of the storm than the CNTL experiments. 


\section{Conclusions}

This paper describes the implementation of a 3DVAR data assimilation system developed for the WRF-NMM system. It has been demonstrated that the desired WRF-NMM forecast fields successfully updated (in terms of grid structure) through the converter utility. The WRFDA system has been upgraded to accept the desired meteorological fields updated through grid conversion utility. The background error covariance code has been upgraded and has been tested successfully to run from WRF-NMM forecast fields.

The performance evaluation of WRF-NMM model with WRFDA data assimilation system for the forecast of three severe tropical cyclones over the Bay of Bengal.

The mean initial positional error has been reduced by 33, 19 and $49 \%$ for Nargis, Aila and Jal cases, respectively. The mean intensity error in terms of CSLP (hPa) and MSW (m/s) suggests that Nargis show more intensity error than that of Aila and Jal cyclones. However, in all the cases, the error reduces significantly in DA analysis than that of GFS analysis. The mean improvement of 19 and $27 \%$ is estimated for CSLP and MSW, respectively.

The mean vector displacement error $(\mathrm{km})$ for all the cases exhibits the improvement of 35,16 , 10,15 and $16 \%$ at $00,24,48,72$ and $96 \mathrm{hr}$, respectively. A reduction of $40 \%$ in LEs $(\mathrm{km})$ is noticed with the forecast length of $24 \mathrm{hr}$ as compared to the forecast length of $96 \mathrm{hr}$ prior to the landfall.

The intensity forecast of the mentioned tropical cyclones is evaluated through central sea level pressure (CSLP; hPa) and maximum sustainable wind $(\mathrm{MSW} ; \mathrm{m} / \mathrm{s})$. Both the experiments overestimated the forecast of CSLP for all the cases. The MSW is well predicted in the case of Nargis and overestimated for Aila and Jal cyclones. The RMSE in intensity forecast suggested the improvement of nearly $27 \%$ in DA experiments than the CNTL in both CSLP and MSW.

The structures of all the cyclones are well simulated with both the experiments. In particular, the inner core structure of cyclones Nargis and Jal is noticeable than Aila case. Also, the DA experiments simulate more pronounced inner core structure of all the cyclones than the CNTL experiments.

\section{Acknowledgements}

The authors thank the Department of Science and Technology (DST), Indo-US Science and Technology Forum (IUSSTF) and Indian National Centre for Information Services (INCOIS), Ministry of Earth Sciences (MoES) for their financial support in different stages to carry out this research work. They would like to thank Dr S R H Rizvi and Dr X-Y Huang of Mesoscale Microscale Meteorology (MMM), NCAR and Dr S G Gopalakrishnan, HRD, AOML, NOAA for their time-to-time help and suggestion im preparation of the manuscript. The authors acknowledge National Center for Environmental Prediction (NCEP) for providing Final Analysis (GFS) forecast field and observational data for model integration and assimilation and India Meteorological Department (IMD) for the best-fit track and intensity observations used in the present study. The authors are also thankful to reviewers for their valuable suggestions/comments to improve this manuscript.

\section{Appendix A}

List of WRF-NMM variables packed by 'E2C' converter utility to be used by WRFDA and its 'gen_be' utility.

\begin{tabular}{|c|c|c|c|c|c|c|}
\hline WRF-NMM & $\begin{array}{l}\text { WRFDA vari- } \\
\text { able (desired) }\end{array}$ & Dimension & Taggering & Units & Description & Remarks \\
\hline $\mathrm{U}$ & $\mathrm{U}$ & $3 \mathrm{D}$ & $\mathrm{X}$ & $\mathrm{m} \mathrm{s}^{-1}$ & $\mathrm{X}$-wind component & \\
\hline V & $\mathrm{V}$ & $3 \mathrm{D}$ & $\mathrm{Y}$ & $\mathrm{m} \mathrm{s}^{-1}$ & Y-wind component & \\
\hline $\mathrm{W}$ & $\mathrm{W}$ & $3 \mathrm{D}$ & $\mathrm{Z}$ & $\mathrm{m} \mathrm{s}^{-1}$ & Vertical velocity & \\
\hline U10 & U10 & $2 \mathrm{D}$ & - & $\mathrm{m} \mathrm{s}^{-1}$ & $\begin{array}{l}10 \mathrm{~m} \mathrm{X} \text {-wind } \\
\text { component }\end{array}$ & \\
\hline V10 & V10 & $2 \mathrm{D}$ & - & $\mathrm{m} \mathrm{s}^{-1}$ & $\begin{array}{l}10 \mathrm{~m} \mathrm{Y} \text {-wind } \\
\text { component }\end{array}$ & \\
\hline
\end{tabular}




\begin{tabular}{|c|c|c|c|c|c|c|}
\hline WRF-NMM & $\begin{array}{l}\text { WRFDA vari- } \\
\text { able (desired) }\end{array}$ & Dimension & Taggering & Units & Description & Remarks \\
\hline $\mathrm{T} 2$ & $\mathrm{~T} 2$ & $2 \mathrm{D}$ & - & K & $2 \mathrm{~m}$ temperature & \\
\hline QS & Q2 & $2 \mathrm{D}$ & - & $\mathrm{kg} / \mathrm{kg}$ & $2 \mathrm{~m}$ specific humidity & \\
\hline $\mathrm{T}($ sensible $)$ & $\mathrm{T}$ & $3 \mathrm{D}$ & - & $\mathrm{K}$ & Dry temperature & \\
\hline Q & QVAPOR & $3 \mathrm{D}$ & - & $\mathrm{kg} / \mathrm{kg}$ & Specific humidity & \\
\hline- & QCLOUD & $3 \mathrm{D}$ & - & - & $\begin{array}{l}\text { Cloud water mixing } \\
\text { ratio }\end{array}$ & \\
\hline- & QRAIN & $3 \mathrm{D}$ & - & - & $\begin{array}{l}\text { Rain water mixing } \\
\text { ratio }\end{array}$ & \\
\hline- & QICE & $3 \mathrm{D}$ & & - & Ice mixing ratio & \\
\hline- & QSNOW & $3 \mathrm{D}$ & - & - & Snow mixing ratio & \\
\hline- & QGRAUP & $3 \mathrm{D}$ & - & - & Graupel mixing ratio & \\
\hline $\mathrm{PD}$ & PSFC & $2 \mathrm{D}$ & - & $\mathrm{Pa}$ & Mass in sigma domain & \\
\hline PDTOP & $\mathrm{MU}$ & $2 \mathrm{D}$ & - & $\mathrm{Pa}$ & $\begin{array}{l}\text { Mass in pressure } \\
\text { domain }\end{array}$ & $\begin{array}{l}\text { In NMM, } \\
\text { PDTOP is a } \\
\text { single value, } \\
\text { but we pack as } \\
2 \mathrm{D} \text { array }\end{array}$ \\
\hline ETA1 & ZNW & $1 \mathrm{D}$ & $\mathrm{Z}$ & - & $\begin{array}{l}\text { Sigma in pressure } \\
\text { domain (higher) }\end{array}$ & \\
\hline ETA2 & $\mathrm{ZNU}$ & $1 \mathrm{D}$ & $\mathrm{Z}$ & - & $\begin{array}{l}\text { Sigma in sigma } \\
\text { domain (lower) }\end{array}$ & \\
\hline PT & $\mathrm{P}_{-} \mathrm{TOP}$ & Single value & - & $\mathrm{Pa}$ & Model top pressure & \\
\hline- & MAPFAC_MX & $2 \mathrm{D}$ & - & - & $\begin{array}{l}\text { Map scale factor on } \\
\text { mass grid in } \\
\text { X-direction }\end{array}$ & $\begin{array}{l}\text { Calculated in } \\
\text { converter } \\
\text { program }\end{array}$ \\
\hline DX_NMM & MU0 & $2 \mathrm{D}$ & - & $\mathrm{m}$ & East-west distance & \\
\hline $\mathrm{DX}$ & DX & Single value & - & $\mathrm{m}$ & East-west distance & $\begin{array}{l}\text { Changed in the } \\
\text { global } \\
\text { attribute }\end{array}$ \\
\hline DY & DY & Single value & - & $\mathrm{m}$ & North-south distance & 'do' \\
\hline DX & CF1 & Single value & - & Degree & East-west distance & \\
\hline DY & $\mathrm{CF} 2$ & Single value & - & Degree & North-south distance & \\
\hline- & HGT & $2 \mathrm{D}$ & - & $\mathrm{m}$ & $\begin{array}{l}\text { Terrain height at } \\
\text { mass }\end{array}$ & $\begin{array}{l}\text { Calculated from } \\
\text { surface } \\
\text { geopotential }\end{array}$ \\
\hline Times & Times & $\begin{array}{c}\text { Character } \\
\text { variable }\end{array}$ & - & - & Forecast valid time & \\
\hline TSK & TSK & $2 \mathrm{D}$ & - & K & Skin temperature & \\
\hline SST & $\mathrm{SST}$ & & - & $\mathrm{K}$ & $\begin{array}{l}\text { Sea surface } \\
\text { temperature }\end{array}$ & \\
\hline $\mathrm{F}$ & $\mathrm{F}$ & $2 \mathrm{D}$ & - & $\mathrm{m}^{-1}$ & Coriolis sine term & \\
\hline SOILTB & TMN & $2 \mathrm{D}$ & - & $\mathrm{K}$ & Soil temperature & \\
\hline GLAT & XLAT & $2 \mathrm{D}$ & - & Degree north & $\begin{array}{l}\text { Latitude at mass } \\
\text { points }\end{array}$ & -90 to +90 \\
\hline GLON & XLONG & $2 \mathrm{D}$ & - & Degree east & $\begin{array}{l}\text { Longitude at mass } \\
\text { points }\end{array}$ & -180 to +180 \\
\hline ACSNOW & SNOWC & $2 \mathrm{D}$ & - & & $\begin{array}{l}\text { Flag indicating snow } \\
\text { coverage }\end{array}$ & 1 for snow cover \\
\hline LU_INDEX & LU_INDEX & $2 \mathrm{D}$ & - & - & Land use category & \\
\hline LANDMASK & LANDMASK & $2 \mathrm{D}$ & & & Land mask & $\begin{array}{l}1 \text { for land } \\
0 \text { for water }\end{array}$ \\
\hline- & XLAND & $2 \mathrm{D}$ & - & - & Land mask & $\begin{array}{l}1 \text { for land } \\
2 \text { for water }\end{array}$ \\
\hline $\mathrm{SMC}$ & SMOIS & $3 \mathrm{D}$ & $\mathrm{Z}$ & $\mathrm{m}^{3} \mathrm{~m}^{-3}$ & Soil moisture & $\begin{array}{l}\text { Levels below } \\
\text { ground }\end{array}$ \\
\hline STC & TSLB & $3 \mathrm{D}$ & $\mathrm{Z}$ & $\mathrm{K}$ & Soil temperature & $\begin{array}{l}\text { Levels below } \\
\text { ground }\end{array}$ \\
\hline
\end{tabular}




\begin{tabular}{|c|c|c|c|c|c|c|}
\hline WRF-NMM & $\begin{array}{l}\text { WRFDA vari- } \\
\text { able (desired) }\end{array}$ & Dimension & Taggering & Units & Description & Remarks \\
\hline SEAICE & SEAICE & $2 \mathrm{D}$ & - & - & Sea ice flag & \\
\hline IVGTYP & IVGTYP & $2 \mathrm{D}$ & - & - & Vegetation category & \\
\hline ISLTYP & ISLTYP & $2 \mathrm{D}$ & - & - & $\begin{array}{l}\text { Dominant soil } \\
\text { category }\end{array}$ & \\
\hline VEGFRA & VEGFRA & $2 \mathrm{D}$ & - & - & Vegetation fraction & \\
\hline SNOWH & SNOWH & $2 \mathrm{D}$ & - & $\mathrm{m}$ & Snow depth & \\
\hline
\end{tabular}

\section{Appendix B}

\section{da_setup_firstguess_wrf_nmm_regional:}

It sets up analysis first guess (FG) for WRFDA with WRF-NMM forecasts.

\section{da_transfer_wrf_nmm_regional_to_xb:}

It transfers relevant WRF-NMM fields, packed by 'E2C' converter utility in Xb-array.

\section{da_transfer_xatowrf_nmm_regional:}

Converts analysis increments to WRF-NMM increments to be written.

\section{da_write_increments_for_wrf_nmm_regional:}

It writes analysis increments (in binary format) for the desired WRF-NMM variables which need to be updated.

\section{da_llxy_rotated_latlon:}

It incorporates rotated lat./long. map projection in WRFDA.

\section{References}

Barker D M, Huang W, Guo Y-R, Bourgeois A J and Xiao Q N 2004 A Three-dimensional variational data assimilation system for MM5: Implementation and initial results; Mon. Wea. Rev. 132 897-914.

Barker D M, Huang X-Y, Liu Z, Auligne T, Zhang X, Rugg S, Ajjaji R, Bourgeous A, Bray J, Che Y, Demirtas M, Guo Y R, Henderson T, Huang W, Lin H C, Michalakes J, Rizvi S R H and Zhang X 2012 The weather research and forecasting model's community variational/ensemble data assimilation system WRFDA; Bull. Am. Meteorol. Soc. 93 831-843.

Bhaskar Rao D V and Hariprasad D 2006 Numerical prediction of the Orissa super cyclone (1999), sensitivity to the parameterisation of convection, boundary layer and explicit moisture processes; Mausam 57 61-78.

Courtier P and Talagrand O 1987 Variational assimilation of meteorological observations with the adjoint vorticity equation-II: Numerical results; Quart. J. Roy. Meteorol. Soc. 113 1329-1347.
Courtier P, Derber J, Errico R, Louis J F and Vukicevic T 1993 Important literature on the use of adjoint, variational methods and Kalman filter in meteorology; Tellus 45A 342-357.

Cressman G 1959 An operational objective analysis system; Mon. Wea. Rev. 87 367-374.

Daley R 1991 Atmospheric Data Analysis; Cambridge University Press, New York, 457p.

Das A K, Rama Rao Y V, Tallapragada V, Zhang Z, Roy Bhowmik and Sharma A 2014 Evaluation of the Hurricane Weather Research and Forecasting (HWRF) model for tropical cyclone forecasts over the North Indian Ocean (NIO); Nat. Hazards 75 1205-1221.

Derber J C 1989 A variational continuous assimilation technique; Mon. Wea. Rev. 117 2437-2446.

Gandin L S 1963 Objective analysis of meteorological fields. Gidrometeor. Isdaty., Leningrad. [Israel Program for Scientific Translations, Jerusalem]: 242p.

Gandin L S 1988 Complex quality control of meteorological observations; Mon. Wea. Rev. 116 1137-1156.

Gao J, Xue M, Shapiro A and Droegemeier K 1999 A variational method for the analysis of three-dimensional wind fields from two Doppler radars; Mon. Wea. Rev. 127 2128-2142.

Greeshma M M, Srinivas C V, Yesubabu V, Naidu C V, Baskaran R and Venkatraman B 2015 Impact of local data assimilation on tropical cyclone predictions over the Bay of Bengal using the ARW model; Ann. Geophys. 33 805-828.

Guidard V, Fischer C, Nuret M and Džiedžic A 2006 Evaluation of the ALADIN 3D-VAR with observations of the MAP campaign; Meteorol. Atmos. Phys. 92 161173.

Huang X Y, Qingnong X X, Barker D M, Zhang X, Michalakes J, Huang W, Henderson T, Bray J, Chen Y, Ma Z, Dudhia J, Guo Y, Zhang X, Won D, Lin H and Kuo Y 2009 Four-dimensional variational data assimilation for WRF: Formulation and preliminary results; Mon. Wea. Rev. 137 299-314.

Ide K, Courtier P, Ghil M and Lorenc A C 1997 Unified notation for data assimilation: Operational, sequential and variational; J. Meteor. Soc. Japan 75 181-189.

Janjic Z I 1984 Non-linear advection schemes and energy cascade on semi-staggered grids; Mon. Wea. Rev. 112 1234-1245.

Janjic Z I 2003a A nonhydrostatic model based on a new approach; Meteorol. Atmos. Phys. 82 271-285.

Janjic Z I 2003b The NCEP WRF core and further development of its physical package; 5th International SRNWP 
Workshop on Non-Hydrostatic Modeling, Bad Orb, Germany, 27-29 October.

Janjic Z I, Gerrity J P Jr and Nickovic S 2001 An alternative approach to nonhydrostatic modeling; Mon. Wea. Rev. 129 1164-1178.

Jianfeng G U, Xiao Q, Kuo Y H, Barker D M, Jishan X and Xiaoxing M A 2005 Assimilation and simulation of typhoon Rusa (2002) using the WRF system; Adv. Atm. Sci. 22 415-427.

Kalman R E 1960 A new approach to linear filtering and prediction problems; J. Basic Eng. 82 35-45.

Kalnay E 2003 Atmospheric Modeling, Data Assimilation and Predictability; Cambridge University Press, 364p.

Lorenc A C et al. 2000 The Met. Office global three dimensional variational data assimilation scheme; Quart. J. Roy. Meteorol. Soc. 126 2991-3012.

Mandal M, Mohanty U C and Raman S 2004 A study on the impact of parameterization of physical processes on prediction of tropical cyclones over the Bay of Bengal with NCAR/PSU mesoscale model; Nat. Hazards 31 391-414.

Mandal M, Mohanty U C and Das A K 2006 Impact of satellite sensed wind in mesoscale simulation of Orissa super cyclone; Ind. J. Mar. Sci. 35 161-173.

Mohanty U C, Mandal M and Raman S 2004 Simulation of Orissa super cyclone (1999) using PSU/NCAR mesoscale model; Nat. Hazards 31 373-390.

Mohanty U C, Pattanayak S and Osuri K K 2010 Changes in frequency and intensity of tropical cyclones over Indian seas in a warming environment; Disaster Dev. 4 53-77.

Osuri K K, Mohanty U C, Routray A and Mohapatra M 2011 Impact of satellite derived wind data assimilation on track, intensity and structure of tropical cyclones over North Indian Ocean; Int. J. Remote Sens. 33 1627-1652.

Parrish D F and Derber J C 1992 The National Meteorological Center's spectral statistical interpolation analysis system; Mon. Wea. Rev. 120 1747-1763.

Pattanaik S and Rama Rao Y V 2009 Track prediction of very severe cyclone 'Nargis' using high resolution weather research forecasting (WRF) model; J. Earth Syst. Sci. 118 309-329.

Pattanayak S and Mohanty U C 2008 A comparative study on performance of MM5 and WRF models in simulation of tropical cyclones over Indian seas; Curr. Sci. 95923 936.

Pielke Sr R A, Matsui T, Leoncini T N, Nair U, Lu E, Eastman J, Kumar S, Peters-Lidard C, Tian Y and Walko R 2006 A new paradigm for parameterizations in numerical weather prediction and other atmospheric models; Nat. Wea. Digest. 30 93-99.

Prasad K, Ramarao Y V and Sen S 1997 Tropical cyclone track prediction by a high resolution limited area model using synthetic observation; Mausam 48 351-366.

Prashant K, Harishkumar K P and Pal P K 2012 Impact of Oceansat-2 Scatterometer Winds and TMI Observations on Phet Cyclone Simulation; IEEE Trans. Geo. Rem. Sensing 51 3774-3779.

RSMC-tropical cyclones 2009 A report on cyclonic disturbances over North Indian Ocean during 2008, New Delhi, India; India Meteorological Department, 108p.

RSMC-tropical cyclones 2010 A report on cyclonic disturbances over North Indian Ocean during 2009, New Delhi, India; India Meteorological Department, 122p.
RSMC-tropical cyclones 2011 A report on cyclonic disturbances over North Indian Ocean during 2010, New Delhi, India; India Meteorological Department, $162 \mathrm{p}$

Sandeep S, Chandrasekar A and Singh D 2006 The impact of assimilation of AMSU data for the prediction of a tropical cyclone over India using a mesoscale model; Int. J. Rem. Sensing 27 4621-4653.

Singh R, Kishtawal C M, Pal P K and Joshi P C 2012 Improved tropical cyclone forecasts over north Indian Ocean with direct assimilation of AMSU-A radiances; Meteorol. Atmos. Phys. 115 15-34.

Singh R, Kishtawal C M, Pal P K and Joshi P C 2011 Assimilation of the multisatellite data into the WRF model for track and intensity simulation of the Indian Ocean tropical cyclones; Meteorol. Atmos. Phys. 111 103-119.

Singh R, Pal P K, Kishtawal C M and Joshi P C 2008 The impact of variational assimilation of SSM/I and QuikSCAT satellite observations on the numerical simulation of Indian Ocean Tropical Cyclones; Wea. Forecasting 23 460-476.

Skamarock W C, Klemp J B, Dudhia J, Gill D O, Barker D M, Wang W and Powers J G 2005 A Description of the Advanced Research WRF Version 2, NCAR Technical Note NCAR/TN-468+STR, https://doi.org/10.5065/ D6DZ069T.

Srinivas C V, Venkatesan R, Vesubabu V and Nagaraju C 2010 Impact of assimilation of conventional and satellite meteorological observations on the numerical simulation of a Bay of Bengal Tropical Cyclone of Nov 2008 near Tamilnadu using WRF model; Meteor. Atmos. Phys. 110 $19-44$.

Srinivas C V, Yesubabu V, Venkatraman B and Ramakrishna S S V S 2012 Numerical simulation of cyclonic storms FANOOS, NARGIS with assimilation of conventional and satellite observations using 3-D-VAR; Nat. Hazards 63 867-889.

Srinivas C V, BhaskarRao D V, Yesubabu V, Baskaran R and Venkatraman B 2013a Tropical cyclone predictions over the Bay of Bengal using the high-resolution advanced research weather research and forecasting model; Quart. J. Roy. Meteorol. Soc. 139 1810-1825.

Srinivas C V, Yesubabu V, Ramakrishna S S V S and Venkatraman B 2013b Real-time prediction of a severe cyclone 'Jal' over Bay of Bengal using a high resolution mesoscale model WRF (ARW); Nat. Hazards 65 331-357.

Stauffer D R and Seaman N L 1990 Use of four-dimensional data assimilation in a limited-area mesoscale model. Part I: Experiments with synoptic-scale data; Mon. Wea. Rev. 118 1250-1277.

Wu B, Verlinde J and Sun J 2000 Dynamical and microphysical retrievals from Doppler radar observations of a deep convective cloud; J. Atmos. Sci. $\mathbf{5 7}$ $262-283$.

Wu W S, Purser R J and Parrish D F 2002 Threedimensional variational analysis with spatially inhomogeneous covariances; Mon. Wea. Rev. 130 2905-2916.

Xiao Q, Kuo Y H, Sun J, Lee W C, Barker D M and Lim E 2007 An approach of Doppler reflectivity data assimilation and its assessment with the inland QPF of Typhoon Rusa (2002) at landfall; J. Appl. Meteorol. 46(1) 14-22. 
Xiao Q, Kuo Y H, Sun J, Lee W C, Lim E, Guo Y R and Barker DM 2005 Assimilation of Doppler radar observations with a regional 3DVAR system: Impact of Doppler velocities on forecasts of a heavy rainfall case; J. Appl. Meteorol. 44 768-788.

Corresponding editor: KAVIRAJAN RAJENDRAN
Yesubabu V, Srinivas C V, Hariprasad K B R R and Baskaran R 2013 A study on the impact of observation assimilation on the numerical simulation of tropical cyclones Jal and Thane using 3-D-Var; Pure Appl. Geophys. 171 2023-2042. 